\title{
A pathway analysis of global aerosol processes
}

\author{
N. A. J. Schutgens and P. Stier \\ Department of Physics, University of Oxford, Parks Road, Oxford, OX1 3PU, UK \\ Correspondence to: N. A. J. Schutgens (schutgens@physics.ox.ac.uk) \\ Received: 15 May 2014 - Published in Atmos. Chem. Phys. Discuss.: 10 June 2014 \\ Revised: 19 September 2014 - Accepted: 28 September 2014 - Published: 6 November 2014
}

\begin{abstract}
We present a detailed budget of the changes in atmospheric aerosol mass and numbers due to various processes: emission (including instant condensation of soluble biogenic emissions), nucleation, coagulation, $\mathrm{H}_{2} \mathrm{SO}_{4}$ condensation and in-cloud production, aging and deposition. The budget is created from monthly averaged tracer tendencies calculated by the global aerosol model ECHAM5.5-HAM2 and allows us to investigate process contributions at various length-scales and timescales. As a result, we show in unprecedented detail what processes drive the evolution of aerosol. In particular, we show that the processes that affect aerosol masses are quite different from those that affect aerosol numbers. Condensation of $\mathrm{H}_{2} \mathrm{SO}_{4}$ gas onto preexisting particles is an important process, dominating the growth of small particles in the nucleation mode to the Aitken mode and the aging of hydrophobic matter. Together with in-cloud production of $\mathrm{H}_{2} \mathrm{SO}_{4}$, it significantly contributes to (and often dominates) the mass burden (and hence composition) of the hydrophilic Aitken and accumulation mode particles. Particle growth itself is the leading source of number densities in the hydrophilic Aitken and accumulation modes, with their hydrophobic counterparts contributing (even locally) relatively little. As expected, the coarse mode is dominated by primary emissions and mostly decoupled from the smaller modes. Our analysis also suggests that coagulation serves mainly as a loss process for number densities and that, relative to other processes, it is a rather unimportant contributor to composition changes of aerosol. The analysis is extended with sensitivity studies where the impact of a lower model resolution or pre-industrial emissions is shown to be small. We discuss the use of the current budget for model simplification, prioritization of model improvements, identification of potential structural model errors and model evaluation against observations.
\end{abstract}

\section{Introduction}

In the past decennia, the importance of atmospheric aerosol to the Earth's climate and biosphere has become increasing clear. Aerosols change the global radiation budget both directly (Angstrom, 1962) and indirectly (Twomey, 1974; Albrecht, 1989). They affect the temperature structure of the atmosphere (Hansen et al., 1997; Lohmann and Feichter, 2005) and may have consequences for the hydrological cycle (Lohmann and Feichter, 1997). Dust aerosols transport nutrients for the biosphere over long distances (Vink and Measures, 2001; McTainsh and Strong, 2007; Maher et al., 2010; Lequy et al., 2012). Finally, anthropogenic aerosols can pose health hazards for humans (Dockery et al., 1993; Brunekreef and Holgate, 2002; Ezzati et al., 2002; Smith et al., 2009; Beelen et al., 2013).

To increase our understanding of the role played by aerosols, increasingly sophisticated models have been built over the past 10-20 years (Ghan and Schwartz, 2007). The early models represented only a single aerosol species such as sulfate or dust (Langner and Rodhe, 1991; Feichter et al., 1996; Tegen and Lacis, 1996; Roelofs et al., 1998; Lohmann et al., 1999; Rasch et al., 2000). Following that, models started to simulate a combination of aerosol species that were externally mixed, (Takemura et al., 2000; Chin et al., 2002). These days several models exist that allow time-varying sizes and species compositions of aerosol particles (Adams and Seinfeld, 2002; Easter et al., 2004; Liao et al., 2004; Liu et al., 2005; Stier et al., 2005; Spracklen et al., 2005; Bauer et al., 2008; Seland et al., 2008; Yu and Luo, 2009; Aan de Brugh et al., 2011). This increase in sophistication allowed the inclusion of more processes: from emission, transport and deposition for the earlier models to new particle formation, coagulation and gaseous condensation in the latter. That added detail in simulation comes at a cost in the form of CPU resources. 
It is not clear to what extent the increased detail has led to better representation of the physical aerosol system. Aerosol Comparisons between Observations and Models (AEROCOM) is a community effort to intercompare global aerosol models and evaluate them against observations (Kinne et al., 2006; Schulz et al., 2006; Textor et al., 2006, 2007; Koffi et al., 2012; Myhre et al., 2013; Samset et al., 2013; Stier et al., 2013). This work has led to many valuable insights into what models can and cannot do. At times it has even allowed the community to identify structural deficiencies in the models, driving the ever increasing sophistication mentioned earlier.

The preceding paragraphs beg the question: what processes are important? It is unlikely that they are all equally relevant so what are the simplest structural requirements for aerosol modeling? Given that most processes operate over a range of particle sizes, where exactly is a certain process important? And how? Conceivably, the sophistication of an aerosol module may trump that of the host model's other modules. Is that necessary? There is as well the issue of the increased demand on CPU resources by aerosol modules, which may or may not be justified. Liu et al. (2012) and Ghan et al. (2012) presented a simplified aerosol model that, according to several metrics, performs similarly to the original more complex model. In this paper, we will define importance as the impact a process has on the mass and number evolution of aerosol relative to the combined impact of all processes.

It has become common practice to assess the importance of newly added processes through sensitivity studies where the model is run twice, once with and once without that new process. The resulting fields of e.g. aerosol optical thickness (AOT) are then compared to understand the importance of that process. The limitation of this very useful approach is that it treats the model as a black box and only allows understanding of how the model operates through inference. Also, when a process is turned off, other processes necessarily become more important (due to the required mass balance) and the simulation is changed fundamentally. So the aforementioned inference is far from straight forward, barring obvious statements like wet deposition removes aerosol.

Recently, emulators have been used to study the sensitivity of an aerosol model to parametric uncertainty (Lee et al., 2012, 2013). These studies have yielded a wealth of information on process contributions to uncertainty in cloud condensation nuclei $(\mathrm{CCN})$ estimates. Parametric uncertainty studies, however, do not tell us which process is the most important to the simulation, whether there is a hierarchy in process importance and how a process operates (again, the model is treated as a black box).

Pathway analysis is a methodology to assess how aerosols are processed in a model and which processes are important. It offers a budget of the model tendencies that affect all tracers that are used to represent the aerosols. The basic idea is simple and an extension of the emission/deposition bud- gets that many models routinely produce. Because pathway analysis offers a relative budget of the individual processes as they are represented in a model, it offers a systematic approach for the reduction of the complexity of (global) aerosol models, thereby allowing us to build faster and leaner aerosol modules for use in climate simulations or data-assimilation experiments. Likewise, it helps identify processes that may contain important structural errors and helps prioritize model improvements.

In this paper, we present a pathway analysis for ECHAM5.5-HAM2 (Stier et al., 2005; Zhang et al., 2012) with the M7 microphysics module (Vignati et al., 2004). The challenge in this pathway analysis is to visualize the aerosol processes acting on 25 tracers (18 for masses and 7 for numbers) through 121 tendencies (17 for emissions, 25 for depositions and 79 for remaining processes like nucleation and coagulation). The M7 microphysics module in ECHAM-HAM (ECHAM-Hamburg Aerosol Module) is also implemented in regional aerosol models like the Consortium for Small Scale Modeling (COSMO) and high-resolution limited-area model (HIRLAM), and is rather similar to the Global Model of Aerosol Processes (GLOMAP) module in the global aerosol model HadGEM-UKCA (Hadley Centre Global Environment Model - UK Chemistry and Aerosol).

In this paper, we start in Sect. 2 with an explanation of the ECHAM5.5-HAM2 model and in particular the processes that govern aerosol evolution. In Sect. 3, we will describe our methodology. Next, we will briefly discuss a year-long simulation of ECHAM5.5-HAM2 with a special focus on the contribution from the different aerosol modes (Sect. 4.1). In Sect. 4.2, the global lifetimes of aerosol species, aerosol modes and aerosol species per mode will be discussed, while Sect. 4.3 examines the global transfer of mass and numbers among the aerosol modes. A detailed analysis of processes per aerosol mode is given in Sect. 4.4. The sensitivity of this analysis to model assumptions like grid resolution and emission data set is considered in Sect. 4.5. We will summarize our work and its results in Sect. 5.

\section{The ECHAM-HAM model}

The global aerosol model ECHAM-HAM consists of an aerosol module HAM (Stier et al., 2005, 2007) coupled to an atmospheric general circulation model ECHAM (Roeckner et al., 2003, 2006). ECHAM-HAM has been used to study non-linearities in aerosol response due to emission changes (Stier et al., 2006a), aerosol effects in a transient climate (Stier et al., 2006b), aerosol activation and cloudprocessing (Roelofs et al., 2006), aerosol indirect effects (Lohmann et al., 2007), the impact of pollution mitigation on climate forcing (Kloster et al., 2008), the impact of volcanic eruptions on climate (Niemeier et al., 2009; Timmreck et al., 2010), the impact of aerosol nucleation on radiative forcing (Makkonen et al., 2009; Kazil et al., 2010), dimming 
Table 1. ECHAM-HAM aerosol mode structure. Mode radii are constrained to the given size ranges. Identification numbers label the modes and are used in figures throughout the paper. Species composition differs by mode. Only the hydrophilic modes experience wet growth due to humidity.

\begin{tabular}{|c|c|c|c|c|c|}
\hline Size class & {$[\mu \mathrm{m}]$} & & $\begin{array}{l}\text { rophilic } \\
\text { species }\end{array}$ & $\begin{array}{l}\mathrm{Hy} \\
\text { id }\end{array}$ & $\begin{array}{l}\text { rophobic } \\
\text { species }\end{array}$ \\
\hline Nucleation & $r \leq 0.005$ & 1 & $\mathrm{SO}_{4}$ & & \\
\hline Aitken & $0.005 \leq r \leq 0.05$ & 2 & $\mathrm{SO}_{4}, \mathrm{POM}, \mathrm{BC}$ & 5 & POM,BC \\
\hline Accumulation & $0.05 \leq r \leq 0.5$ & 3 & $\mathrm{SO}_{4}, \mathrm{POM}, \mathrm{BC}, \mathrm{SS}, \mathrm{DU}$ & 6 & DU \\
\hline Coarse & $r \geq 0.5$ & 4 & $\mathrm{SO}_{4}, \mathrm{POM}, \mathrm{BC}, \mathrm{SS}, \mathrm{DU}$ & 7 & DU \\
\hline
\end{tabular}

and brightening of surface radiation due to aerosols (Folini and Wild, 2011), climate forcing due to secondary organic aerosols (O'Donnell et al., 2011) and aerosol indirect effects due to shipping emissions (Peters et al., 2012) to name but a few studies.

The general circulation model ECHAM was developed at the Max Planck Institute for Meteorology and evolved from the model at the European Centre for Medium-Range Weather Forecasting. It solves the prognostic equations for vorticity, divergence, surface pressure and temperature using spherical harmonics with triangular truncation. Tracers like water vapor, liquid and ice hydrometeors, various trace gases as well as aerosols are advected with a flux-form semiLagrangian transport scheme (Lin and Rood, 1996) on a Gaussian grid. ECHAM can be nudged to meteorological reanalysis fields. More details can be found in Roeckner et al. (2003, 2006).

The aerosol module HAM calculates the global evolution of five aerosol species: sulfate $\left(\mathrm{SO}_{4}\right)$, particulate organic matter (POM), black carbon (BC), sea salt (SS) and dust (DU). These species are the constituents of both internally and externally mixed aerosol particles whose size distribution is represented by seven uni-modal lognormal distributions called modes. These seven modes describe four size classes (nucleation, Aitken, accumulation and coarse) and two hygroscopic classes (hydrophobic and hydrophilic). Most of these modes contain time- and space-varying mixtures of aerosol species; see Table 1. To predict aerosol evolution, ECHAM-HAM (without explicit SOA; see later) uses 25 tracers: 7 for number mixing ratios and 18 for mass mixing ratios. $\mathrm{H}_{2} \mathrm{SO}_{4}$ nucleation and condensation, coagulation and aging are handled by the M7 sub-module by Vignati et al. (2004). The processes described in M7 cause redistribution of aerosol mass and numbers among the modes. Part of HAM is a sulfur cycle model (Feichter et al., 1996) that predicts the evolution of dimethyl sulfide (DMS), sulfur dioxide $\left(\mathrm{SO}_{2}\right)$ and gaseous sulfate $\left(\mathrm{SO}_{4}^{-}\right)$using monthly mean fields of the oxidants $\mathrm{OH}, \mathrm{H}_{2} \mathrm{O}_{2}, \mathrm{NO}_{2}$ and $\mathrm{O}_{3}$, calculated off-line by the MOZART (model for ozone and related chemical tracers) chemical transport model (Horowitz et al., 2003). The aerosol in HAM is affected by the meteorology calculated by
ECHAM, and in turn provides feedback to ECHAM as it affects atmospheric radiative transfer and cloud microphysics.

Over time, various improvements have been made to ECHAM-HAM and currently a distinction is made between the initial version HAM 1 (Stier et al., 2005) and the newer version HAM 2 (Zhang et al., 2012). While using the same modal structure (Table 1), HAM 2 added new parametrizations for nucleation, sea salt and dust emissions, a water uptake scheme based on $\kappa$-Köhler theory and an explicit scheme for secondary organic aerosol (SOA) formation. For a detailed overview of the differences between HAM 1 and HAM 2; see Zhang et al. (2012) who also define the default choices for an ECHAM5.5-HAM2 experiment.

In this paper, we will use ECHAM5.5-HAM2, nudged to ERA-interim meteorological reanalysis for the year 2000. To reduce the complexity of the analysis, we chose to use the implicit SOA modeling scheme from HAM 1 instead of the explicit scheme that was introduced with HAM 2. For computational reasons, the implicit scheme is currently considered the default option. It assumes that a specified fraction $(65 \%)$ of biogenic emissions are soluble and directly condense onto pre-existing hydrophilic aerosol. Thus, particle growth through condensation of volatile gases is considered albeit in an abstract fashion. As a consequence of this modeling approach, the process of organic condensation is included among the emissions (POM mass formation). Over land, this condensation often dominates primary emissions into the hydrophobic Aitken and accumulation modes, but it seldom dominates as a source of total aerosol mass in those modes.

\subsection{Aerosol processes in ECHAM-HAM}

An overview of all possible processes is shown in Table 2 . It lists the physical or chemical process, the code used in many of this paper's figures, the explicit pathways and the species involved. Pathways are indicated by right-pointing arrows, with the numbers on either side indicating the involved modes (1: nucleation, 2: hydrophilic Aitken, 3: hydrophilic accumulation, 4: hydrophilic coarse, 5: hydrophobic Aitken, 6: hydrophobic accumulation, 7: hydrophobic coarse). On the left of the arrow, the mode that loses mass (m) or numbers (n), and on the right of the arrow the mode 
Table 2. Aerosol processes in ECHAM-HAM. The columns present from left to right: the process; the identification code used in various figures; the exact pathway, using numbers to identify mode and letters to identify number (n) or mass (m) tendencies; the species involved. In the right two columns, specific aging processes are detailed. In ECHAM-HAM they are the instantaneous result of some process mentioned on the left.

\begin{tabular}{|c|c|c|c|c|c|c|}
\hline \multirow[b]{2}{*}{ Process } & \multirow[b]{2}{*}{ Code } & \multirow[b]{2}{*}{ Pathway } & \multirow[b]{2}{*}{ Species } & \multicolumn{3}{|c|}{ aging } \\
\hline & & & & Code & Pathway & Species \\
\hline Emission & $\mathrm{SO} 4$ & $\rightarrow 2 \mathrm{n}, \mathrm{m}$ & $\mathrm{SO}_{4}$ & & & \\
\hline Emission & $\mathrm{SO} 4$ & $\rightarrow 3 \mathrm{n}, \mathrm{m}$ & $\mathrm{SO}_{4}$ & & & \\
\hline Emission & SO4 & $\rightarrow 4 \mathrm{n}, \mathrm{m}$ & $\mathrm{SO}_{4}$ & & & \\
\hline Emission & POM & $\rightarrow 2 \mathrm{n}, \mathrm{m}$ & POM & & & \\
\hline Emission & POM & $\rightarrow 3 \mathrm{~m}$ & POM & & & \\
\hline Emission & $\mathrm{POM}$ & $\rightarrow 5 \mathrm{n}, \mathrm{m}$ & POM & & & \\
\hline Emission & SS & $\rightarrow 3 \mathrm{n}, \mathrm{m}$ & SS & & & \\
\hline Emission & SS & $\rightarrow 4 \mathrm{n}, \mathrm{m}$ & SS & & & \\
\hline Emission & $\mathrm{BC}$ & $\rightarrow 5 \mathrm{n}, \mathrm{m}$ & $\mathrm{BC}$ & & & \\
\hline Emission & DU & $\rightarrow 6 \mathrm{n}, \mathrm{m}$ & DU & & & \\
\hline Emission & DU & $\rightarrow 7 \mathrm{n}, \mathrm{m}$ & DU & & & \\
\hline Nucleation & NCL & $\rightarrow 1 \mathrm{n}, \mathrm{m}$ & $\mathrm{SO}_{4}$ & & & \\
\hline Condensation & CND & $\rightarrow 1 \mathrm{~m}$ & $\mathrm{SO}_{4}$ & & & \\
\hline Condensation & CND & $\rightarrow 2 \mathrm{~m}$ & $\mathrm{SO}_{4}$ & & & \\
\hline Condensation & CND & $\rightarrow 3 \mathrm{~m}$ & $\mathrm{SO}_{4}$ & & & \\
\hline Condensation & CND & $\rightarrow 4 \mathrm{~m}$ & $\mathrm{SO}_{4}$ & & & \\
\hline Condensation & CND & $\rightarrow 5$ & $\mathrm{SO}_{4}$ & CAG & $5 \mathrm{n}, \mathrm{m} \rightarrow 2 \mathrm{n}, \mathrm{m}$ & $\mathrm{SO}_{4}, \mathrm{POM}, \mathrm{BC}$ \\
\hline Condensation & CND & $\rightarrow 6$ & $\mathrm{SO}_{4}$ & CAG & $6 \mathrm{n}, \mathrm{m} \rightarrow 3 \mathrm{n}, \mathrm{m}$ & $\mathrm{SO}_{4}, \mathrm{DU}$ \\
\hline Condensation & CND & $\rightarrow 7$ & $\mathrm{SO}_{4}$ & CAG & $7 \mathrm{n}, \mathrm{m} \rightarrow 4 \mathrm{n}, \mathrm{m}$ & $\mathrm{SO}_{4}, \mathrm{DU}$ \\
\hline In-cloud production & PRD & $\rightarrow 3 \mathrm{~m}$ & $\mathrm{SO}_{4}$ & & & \\
\hline In-cloud production & PRD & $\rightarrow 4 \mathrm{n}, \mathrm{m}$ & $\mathrm{SO}_{4}$ & & & \\
\hline Coagulation & $\square 11$ & $\ln \rightarrow$ & & & & \\
\hline Coagulation & $\square 12$ & $1 \mathrm{n}, \mathrm{m} \rightarrow 2 \mathrm{~m}$ & $\mathrm{SO}_{4}$ & & & \\
\hline Coagulation & 13 & $1 \mathrm{n}, \mathrm{m} \rightarrow 3 \mathrm{~m}$ & $\mathrm{SO}_{4}$ & & & \\
\hline Coagulation & 14 & $1 \mathrm{n}, \mathrm{m} \rightarrow 4 \mathrm{~m}$ & $\mathrm{SO}_{4}$ & & & \\
\hline Coagulation & 15 & $1 \mathrm{n}, \mathrm{m} \rightarrow 5$ & $\mathrm{SO}_{4}$ & 152 & $5 \mathrm{n}, \mathrm{m} \rightarrow 2 \mathrm{n}, \mathrm{m}$ & $\mathrm{SO}_{4}, \mathrm{POM}, \mathrm{BC}$ \\
\hline Coagulation & $\square 16$ & $1 \mathrm{n}, \mathrm{m} \rightarrow 6$ & $\mathrm{SO}_{4}$ & 163 & $6 \mathrm{n}, \mathrm{m} \rightarrow 3 \mathrm{n}, \mathrm{m}$ & $\mathrm{SO}_{4}, \mathrm{DU}$ \\
\hline Coagulation & 17 & $1 \mathrm{n}, \mathrm{m} \rightarrow 7$ & $\mathrm{SO}_{4}$ & 174 & $7 \mathrm{n}, \mathrm{m} \rightarrow 4 \mathrm{n}, \mathrm{m}$ & $\mathrm{SO}_{4}, \mathrm{DU}$ \\
\hline Coagulation & $\square 22$ & $2 \mathrm{n} \rightarrow$ & & & & \\
\hline Coagulation & 23 & $2 \mathrm{n}, \mathrm{m} \rightarrow 3 \mathrm{~m}$ & $\mathrm{SO}_{4}, \mathrm{POM}, \mathrm{BC}$ & & & \\
\hline Coagulation & 24 & $2 \mathrm{n}, \mathrm{m} \rightarrow 4 \mathrm{~m}$ & $\mathrm{SO}_{4}, \mathrm{POM}, \mathrm{BC}$ & & & \\
\hline Coagulation & 26 & $2 \mathrm{n}, \mathrm{m} \rightarrow 6$ & $\mathrm{SO}_{4}, \mathrm{POM}, \mathrm{BC}$ & 263 & $6 \mathrm{n}, \mathrm{m} \rightarrow 3 \mathrm{n}, \mathrm{m}$ & $\mathrm{SO}_{4}, \mathrm{POM}, \mathrm{BC}, \mathrm{DU}$ \\
\hline Coagulation & 27 & $2 \mathrm{n}, \mathrm{m} \rightarrow 7$ & $\mathrm{SO}_{4}, \mathrm{POM}, \mathrm{BC}$ & 274 & $7 \mathrm{n}, \mathrm{m} \rightarrow 4 \mathrm{n}, \mathrm{m}$ & $\mathrm{SO}_{4}, \mathrm{POM}, \mathrm{BC}, \mathrm{DU}$ \\
\hline Coagulation & 33 & $3 \mathrm{n} \rightarrow$ & & & & \\
\hline Coagulation & $\square 5$ & $5 \mathrm{n} \rightarrow$ & & & & \\
\hline Coagulation & 52 & $5 \mathrm{n}, \mathrm{m} \rightarrow 2 \mathrm{~m}$ & POM, BC & & effectively an ag & eing process \\
\hline Coagulation & 53 & $5 \mathrm{n}, \mathrm{m} \rightarrow 3 \mathrm{~m}$ & POM, BC & & effectively an ag & eing process \\
\hline Redistribution & 口DB & $1 \mathrm{n}, \mathrm{m} \rightarrow 2 \mathrm{n}, \mathrm{m}$ & $\mathrm{SO}_{4}$ & & & \\
\hline Redistribution & RDB & $2 \mathrm{n}, \mathrm{m} \rightarrow 3 \mathrm{n}, \mathrm{m}$ & $\mathrm{SO}_{4}, \mathrm{POM}, \mathrm{BC}$ & & & \\
\hline Redistribution & RDB & $3 \mathrm{n}, \mathrm{m} \rightarrow 4 \mathrm{n}, \mathrm{m}$ & $\mathrm{SO}_{4}, \mathrm{POM}, \mathrm{BC}, \mathrm{DU}, \mathrm{SS}$ & & & \\
\hline Wet deposition & WET & all $\rightarrow$ & $\mathrm{SO}_{4}, \mathrm{POM}, \mathrm{BC}, \mathrm{DU}, \mathrm{SS}$ & & & \\
\hline Dry deposition & DRY & all $\rightarrow$ & $\mathrm{SO}_{4}, \mathrm{POM}, \mathrm{BC}, \mathrm{DU}, \mathrm{SS}$ & & & \\
\hline Sedimentation & SED & all $^{*} \rightarrow$ & $\mathrm{SO}_{4}, \mathrm{POM}, \mathrm{BC}, \mathrm{DU}, \mathrm{SS}$ & ${ }^{*}:$ all, ex & cept nucleation $\mathrm{m}$ & ode \\
\hline
\end{tabular}

that gains mass or numbers are shown. Some processes instantaneously lead to aging of particles. As an example take condensation of $\mathrm{H}_{2} \mathrm{SO}_{4}$ onto hydrophobic accumulation dust particles. This involves the $\mathrm{SO}_{4}$ species, which condenses on the hydrophobic accumulation mode which has no mass tracer for sulfate. Instead, the condensed sulfate and a por- tion of the dust particles are immediately moved to the hydrophilic accumulation mode.

\subsection{Primary emissions}

The emissions of sea salt and dust are based on diagnosed $10 \mathrm{~m}$ wind speeds from the model. Sea salt uses the emission parametrizations by Monahan et al. (1986) 
and Smith and Harrison (1998) as suggested by Guelle et al. (2001). The species is emitted into the hydrophilic accumulation and coarse modes only. Dust emission is based on the scheme by Tegen (2002), as modified by Stier et al. (2005). Dust is emitted into the hydrophobic accumulation and coarse modes and is hence assumed to be hydrophobic initially.

The emissions of sulfate, particulate organic matter and black carbon are based on standard AEROCOM inventories (Stier et al., 2005; Zhang et al., 2012). It is assumed that $2.5 \%$ of emitted $\mathrm{SO}_{2}$ (itself based on an inventory) is emitted as sulfate aerosol with prescribed size, depending on the source. Sulfate from volcanoes is injected at pre-specified heights in the atmosphere into the hydrophilic Aitken (50\%) and accumulation $(50 \%)$ modes. Sulfate from biomass burning is likewise injected at pre-specified heights in the atmosphere into the hydrophilic Aitken (50\%) and accumulation $(50 \%)$ modes. Anthropogenic emissions of sulfate, on the other hand, are distributed over the hydrophilic Aitken $(50 \%, 0 \%)$, accumulation $(50 \%, 50 \%)$ and coarse $(0 \%$, $50 \%$ ) modes depending on the exact source (surface emissions, boundary layer emissions).

Organic carbon emissions distribute $65 \%$ of their mass in the hydrophilic modes and $35 \%$ in the hydrophobic mode. Most sources of organic matter (including wild fires) cause emission into the Aitken mode. The exception is the treatment of biogenic emissions where half of the hydrophilic biogenic material condenses onto Aitken particles and the other half on accumulation particles.

Black carbon, irrespective of source, is emitted into the hydrophobic Aitken mode.

\subsection{Removal processes}

Wet and dry deposition, as well as sedimentation (together called: removal processes), are all modeled in ECHAMHAM. For details we refer to Stier et al. (2005) and Zhang et al. (2012). Both rain-out and below-cloud scavenging of aerosol by water is considered and precipitation can reevaporate. The standard version of ECHAM-HAM does not explicitly model aerosol in hydrometeors (see (Hoose et al., 2008)). Dry deposition is based on a surface resistance model and sedimentation is calculated using Stokes theory. Sedimentation is not considered for the smallest particles (nucleation and Aitken). Removal processes assume that all particles within the mode have the same (wet) mode radius when calculating efficiencies and will remove particles accordingly.

\subsection{Nucleation of $\mathrm{H}_{2} \mathrm{SO}_{4}$ gas}

Binary nucleation of the $\mathrm{H}_{2} \mathrm{SO}_{4}-\mathrm{H}_{2} \mathrm{O}$ system (Seinfeld and Pandis, 2006, Ch. 11) converts sulfate gas into sulfate aerosol. In ECHAM-HAM, two parametrization schemes are used to calculate the formation of new nucleation mode sul- fate aerosol based on environmental conditions. Binary homogenous nucleation is parametrized according to Kazil and Lovejoy (2007) and is the main nucleation mechanism yielding large particle numbers at the top of the troposphere. Boundary layer nucleation events over forest areas is modeled according to cluster activation theory (Kulmala et al., 2006) and parametrized as in Riipinen et al. (2007).

While the parametrization by Kazil and Lovejoy (2007) is based on theory and numerous laboratory experiments, the parametrization by Riipinen et al. (2007) is based on observations at two (European) sites only. See also Kazil et al. (2010) for an evaluation of nucleation processes in ECHAM-HAM.

\subsection{Condensation of $\mathrm{H}_{2} \mathrm{SO}_{4}$ gas}

Sulfate gas condenses easily onto aerosol and cloud particles (Seinfeld and Pandis, 2006, Ch. 12 and 13). In ECHAMHAM, a distinction is made between the condensation of sulfate in cloudy and cloud-free parts of a grid box. In the cloud-free parts, condensation of sulfate gas onto aerosol particles is calculated using the mass balance equation in Fuchs (1964), assuming that in each mode all aerosol particles have the same size (mode radius). The accommodation coefficients (sticking coefficients) are 1.0 for hydrophilic and 0.3 for hydrophobic modes. In the cloudy part of the grid box, it is assumed that all available sulfate gas condenses onto the cloud particles (which are much larger than the aerosol and present a much larger surface). However, the in-cloud condensed sulfate gas is then assumed to redistribute over the aerosol in the grid box. Since HAM 2 does not specifically model aerosol in cloud particles, the cloud-condensed $\mathrm{H}_{2} \mathrm{SO}_{4}$ is allocated to the largest hydrophilic mode available. If no such mode exists in a grid box, the largest hydrophobic mode available is used instead.

Condensation of $\mathrm{H}_{2} \mathrm{SO}_{4}$ onto aerosol is calculated at the mode radii only (size distribution of the modes are ignored). In practice, cloud-condensed $\mathrm{H}_{2} \mathrm{SO}_{4}$ is never allocated to any of the hydrophobic modes.

\subsection{In-cloud production of $\mathrm{H}_{2} \mathrm{SO}_{4}$ aerosol}

A third process for the production of sulfate aerosol species is aqueous-phase oxidation of dissolved $\mathrm{SO}_{2}, \mathrm{~S}(\mathrm{IV})$, into dissolved $\mathrm{SO}_{4}, \mathrm{~S}(\mathrm{VI})$, (Seinfeld and Pandis, 2006, Ch. 7). In $\mathrm{HAM}, \mathrm{SO}_{2}$ dissolves in clouds into $\mathrm{S}(\mathrm{IV})$ products which are subsequently oxidized by $\mathrm{O}_{3}$ and $\mathrm{H}_{2} \mathrm{O}_{2}$ into $\mathrm{SO}_{4}(\mathrm{Fe}-$ ichter et al., 1996). The resulting sulfate aerosol species is allocated to the hydrophilic accumulation and coarse modes (distributed according to available number densities). Oxidation rates are $\mathrm{pH}$ dependent. If no hydrophilic accumulation and coarse mode aerosols exist in a grid box, new hydrophilic coarse aerosol is created, although this rarely happens. In fact, almost all in-cloud produced $\mathrm{H}_{2} \mathrm{SO}_{4}$ is allocated to preexisting hydrophilic accumulation particles. 


\subsection{Coagulation}

In ECHAM-HAM, coagulation is modeled by considering Brownian coagulation processes for the smaller and/or more numerous modes. Coagulation results in a decrease of number densities for intra-modal coagulation (i.e., nucleation particles coagulating with their own kind) or a decrease of number density in one mode and a mass transfer to another (larger or more hydrophilic) mode for inter-modal coagulation. The model for coagulation is based on the work by Fuchs (1964) and represents the change in number density $N$ as

$\frac{\partial N_{i}}{\partial t}=4 \pi N_{i} \sum_{j} \alpha_{i j}\left(D_{i}+D_{j}\right)\left(r_{i}+r_{j}\right) \beta_{i j} N_{j}$,

where $i$ represents the mode whose particles are captured by particles in mode $j . D$ is the diffusivity and $r$ the radius of the particles of a certain mode. For inter-modal coagulation $\alpha_{i j}=1$, but for intra-modal coagulation $\alpha_{i i}=\frac{1}{2}$. Fuchs introduced the factor $\beta_{i j}$ that corrects the Brownian diffusion of a smaller particle close to a larger particle. The coagulation efficiency is 1 for all modes.

Not all possible coagulation processes are considered in ECHAM-HAM. For a list of those represented; see Table 2. In particular, intra-modal coagulation of the hydrophobic accumulation and coarse modes and the hydrophilic coarse mode are ignored, the latter in contrast to what is mentioned in Vignati et al. (2004).

The solution of Eq. (1) for one model time step is the analytical solution assuming that all $N_{j \neq i}$ are constant. Our model for coagulation assumes all particles of the same mode have an identical radius (being the mode radius of the number size distribution). For typical aerosol sizes, intra-modal coagulation increases as size decreases, while inter-model coagulation is more effective when the coagulating particles are more disparate in size (Seinfeld and Pandis, 2006, Sect. 13.3.1). As a consequence, the use of a single size for all particles in a mode may have an impact on coagulation. In addition, no consideration has been given to the impact of shear flow, turbulence, gravitational settling or electrical forces on coagulation. Finally, the theory by Fuchs assumes spherical particles which may not be entirely appropriate for black carbon or dust particles.

\subsection{Aging of hydrophobic aerosol}

Hydrophobic aerosol becomes hydrophilic through the collection of hydrophilic species like sulfate or carbons. In HAM, the collection of hydrophilic sulfate onto hydrophobic carbon and dust aerosols is modeled explicitly. Hydrophilic carbons by themselves do not cause aging (we also do not consider chemical aging). The hydrophilic species are collected in the hydrophobic modes through either condensation of sulfate gas or coagulation with hydrophilic aerosol. This collection instantaneously leads to a transfer of the hy- drophilic species and part of the hydrophobic aerosol to a hydrophilic mode. The following pathways exist:

- condensation of sulfate gas onto particles of the hydrophobic modes and subsequent transfer to hydrophilic modes of the same size class,

- coagulation of smaller hydrophilic particles with the hydrophobic modes and subsequent transfer to the hydrophilic mode of the same size class as the hydrophobic mode,

- coagulation of particles of the hydrophobic Aitken mode with hydrophilic Aitken and accumulation modes.

The resulting mass transfer for the latter pathway (note there will be no number transfer) is calculated using the coagulation equation. The mass and numbers transfer for the first two pathways are calculated by assuming the $\mathrm{SO}_{4}$ accumulated in one time step coats as many hydrophobic mode particles as possible with a single layer of sulfate. Hence this calculation uses total accumulated $\mathrm{SO}_{4}$ mass and the radius of the hydrophobic mode. Only for a steady state will this provide an accurate estimate of the tendency.

The aging processes represented in ECHAM-HAM are shown in Table 2 in the columns on the right.

\subsection{Redistribution among hydrophilic modes}

Each mode has a spatiotemporally varying mode radius that should remain within its allotted size range (see Table 1). As a result of aforementioned processes, such as condensation and production of $\mathrm{H}_{2} \mathrm{SO}_{4}$ or intermodal coagulation, particle sizes of hydrophilic modes may grow. When the particles becomes too large, part of the aerosol in such a hydrophilic mode will be transferred to the next larger hydrophilic mode. Conceptually, part of the assumed size distribution of the mode will extend beyond an allowed maximum size and will be moved to the next larger mode.

This process is sometimes called mode merging, but redistribution is a more accurate description.

\section{Methodology}

In this paper, process refers to a physical or chemical event that modifies aerosol mass and number densities. The processes that we will consider are nucleation of $\mathrm{H}_{2} \mathrm{SO}_{4}$, emission of primary aerosol (including instant condensation of soluble biogenic emissions), condensation of $\mathrm{H}_{2} \mathrm{SO}_{4}$ onto pre-existing aerosol, in-cloud production of liquid phase $\mathrm{H}_{2} \mathrm{SO}_{4}$, coagulation of aerosol, aging of aerosol as well as wet and dry deposition and sedimentation. In the model, the effect of these processes is represented by tendencies. A single process can be described by several tendencies, e.g., the condensation of $\mathrm{H}_{2} \mathrm{SO}_{4}$ is handled in the model through seven mass tendencies (one for each mode). All tendencies 


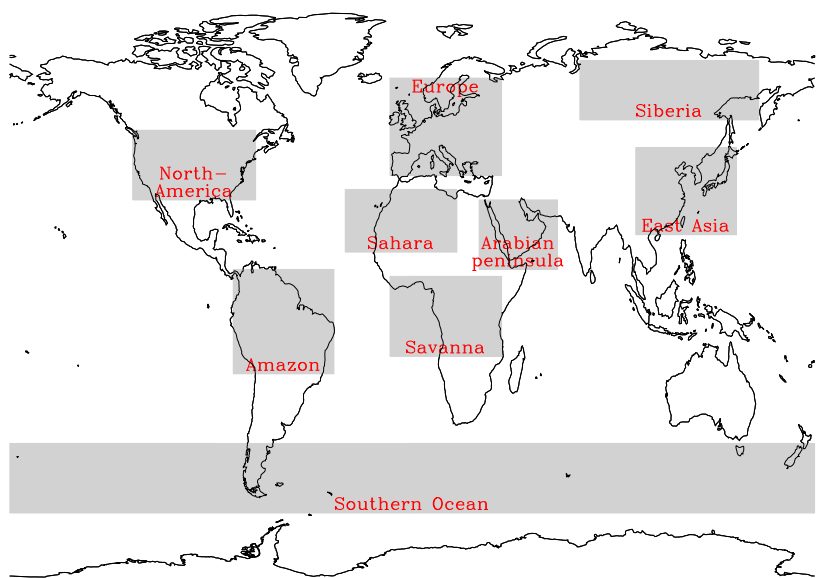

Figure 1. Definition of the regions that will be used for part of the analysis in this paper.

that modify any single aerosol mode are called the pathways into and out of that mode. Note that these tendencies do not include tendencies due to tracer transport but are purely due to physical and chemical processes in the atmospheric column.

Conceptually, the mass density in a grid box of the model is updated as follows:

$$
\begin{aligned}
& m(t+\delta t)=m(t)+\delta m_{\text {emission }}+\delta m_{\text {nucleation }} \\
& +\delta m_{\text {condensation }}+\ldots-\delta m_{\text {deposition }}-\ldots
\end{aligned}
$$

where the tendencies $\delta m \geq 0$. For our analysis, model tendencies for aerosol mass and number densities due to the various processes at each time step were stored and averaged over a month:

$\Delta m_{\text {emission }}=\frac{1}{T} \int_{0}^{T} \delta m_{\text {emission }} \mathrm{d} t$.

Tendencies can be distinguished into gain (e.g., emission) and loss (e.g., deposition) tendencies, depending on whether they increase or decrease the tracer they affect. The sum of all gain tendencies will be called the total gain tendency. Fractional tendencies are calculated by dividing the tendency due to one (gain or loss) process by the total (gain or loss) tendency:

$f_{\text {emission }}=\frac{\Delta m_{\text {emission }}}{\sum_{\text {all gain processes }} \Delta m}$.

These fractional tendencies $(0 \leq f \leq 1)$ provide a lot of information on which processes are dominant and which are not. Although fractional tendencies can be calculated for each model grid box, it will make more sense to calculate them for an atmospheric column, as a zonal average or for a

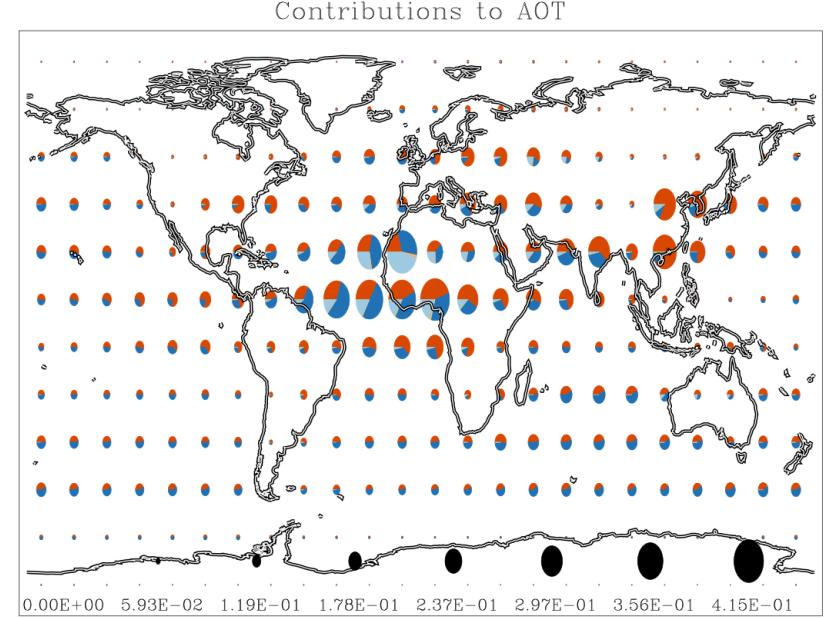

Contributions to $\mathrm{CCN}$ at $\mathrm{S}=1 \%\left[\mathrm{~m}^{-2}\right]$

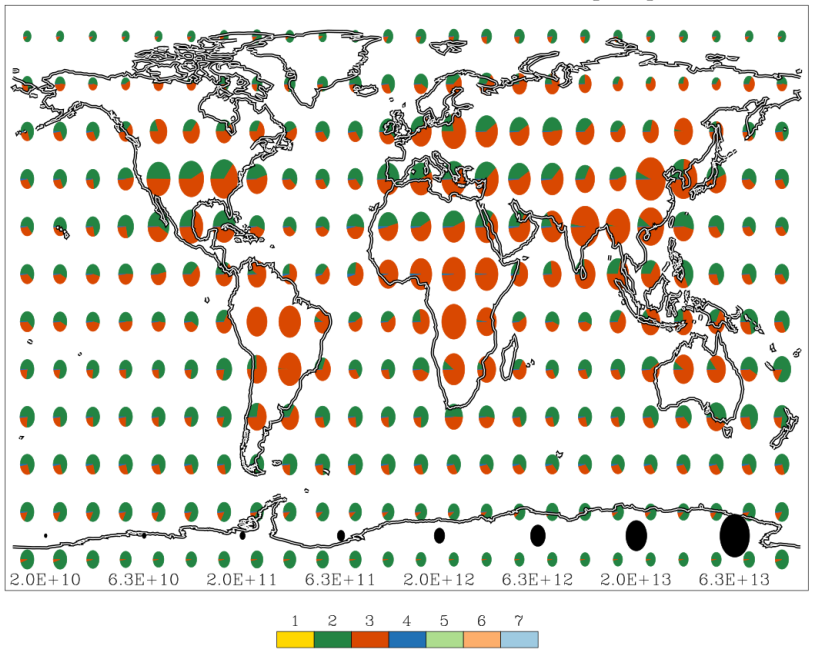

Figure 2. Contributions by different modes to AOT and CCN for the baseline experiment. The pie chart colors show contribution by mode (see legend below lowest panel); the pie chart's size shows the overall magnitude (legend at the bottom of each panel). From top to bottom: AOT at $550 \mathrm{~nm}$ (linear scale); column-integrated $\mathrm{CCN}$ at $S=1 \%$ (logarithmic scale).

region (see Fig. 1 for a definition of the regions used in this paper).

In this paper, we will analyze three different experiments, all conducted with ECHAM5.5-HAM2. First, a base-line experiment with present-day emissions at a grid resolution of T63L31 (this indicates a triangular truncation of the spherical harmonics at zonal wave number 63 , giving grid boxes of approximately $1.9^{\circ} \times 1.9^{\circ}$ or $\sim 210 \mathrm{~km}$ at the equator, and 31 atmospheric levels). Second, two sensitivity studies where either the model resolution (T31L19, approximately $3.7^{\circ} \times 3.7^{\circ}$ or $\sim 420 \mathrm{~km}$ at the equator, and 19 atmospheric levels) or the emissions (pre-industrial) were changed. The baseline experiment has a setup identical to the baseline experiment in Zhang et al. (2012), with the exception of SOA 
for which we use the implicit scheme, where soluble biogenic emissions are assumed to condense immediately onto preexisting hydrophilic aerosol (currently this implicit scheme is considered the default option).

\section{Analysis}

\subsection{Contributions per mode to model observables}

Before analyzing the processes in ECHAM5.5-HAM2, we want to understand their consequence in terms of the contributions that the different modes give to essential aerosol fields like $\mathrm{AOT}^{1}, \mathrm{PM}_{2.5}{ }^{2}, \mathrm{CCN}^{3}$ and the distribution of black carbon mass; see Fig. 2 and 3. Note that the global distributions of these fields are as expected; there is a notable land-ocean contrast and values tend to be highest near known sources of aerosol, either man made or natural.

We see in all cases that the hydrophilic accumulation mode has a significant and often dominating contribution. AOT is determined by the hydrophilic accumulation mode and the hydrophobic and hydrophilic coarse modes (note the absence of any significant contribution by the hydrophobic accumulation mode). Over polluted regions, the hydrophilic accumulation mode dominates, while over the Sahara and the Saharan outflow coarse particles dominate. Over the ocean, it is typically a mix of hydrophilic accumulation and coarse modes that defines AOT. In contrast, the coarse modes dominate $\mathrm{PM}_{2.5}$ everywhere although sizeable contributions from the hydrophilic accumulation mode exist locally. Note that over land, the hydrophobic coarse mode has usually a significant contribution. $\mathrm{CCN}$ at supersaturation $S=1 \%$, on the other hand, are dominated by hydrophilic particles of smaller size classes: Aitken and accumulation modes. Over remote oceans, the Aitken mode actually dominates $\mathrm{CCN}$, although there is no primary emission of Aitken size particles there. At low $S=0.1 \%$ values (not shown), $\mathrm{CCN}$ is dominated by the hydrophilic accumulation mode. Finally, most black carbon is present in the hydrophilic accumulation mode although a sizeable mass fraction is carried by the hydrophobic Aitken mode (into which it is emitted).

\subsection{Lifetimes and loss rates}

In this section, we will analyze typical timescales in our aerosol simulations. In particular, the lifetimes (Seinfeld and Pandis, 2006, Ch. 2) of aerosol species and modes will be considered:

$\tau=\frac{B}{I}=\frac{B}{R}$

where $B$ is the global burden of a species or mode, $I$ its global introduction (through e.g., emissions, nucleation or

\footnotetext{
1 aerosol optical thickness

${ }^{2}$ mass of particulate matter with sizes less than $2.5 \mu \mathrm{m}$

3 cloud condensation nuclei
}

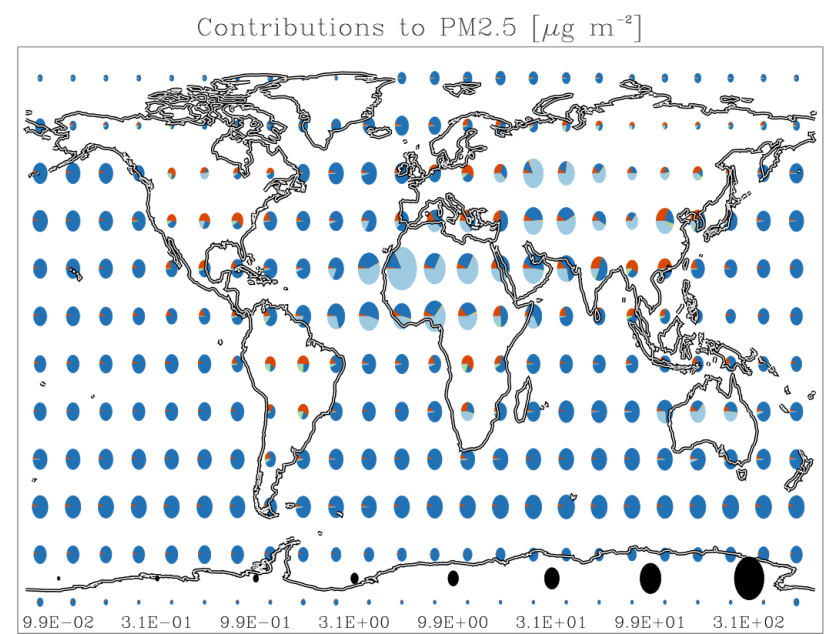

Contributions to $\mathrm{BC}$ mass $\left[\mathrm{kg} \mathrm{m}^{-2}\right]$

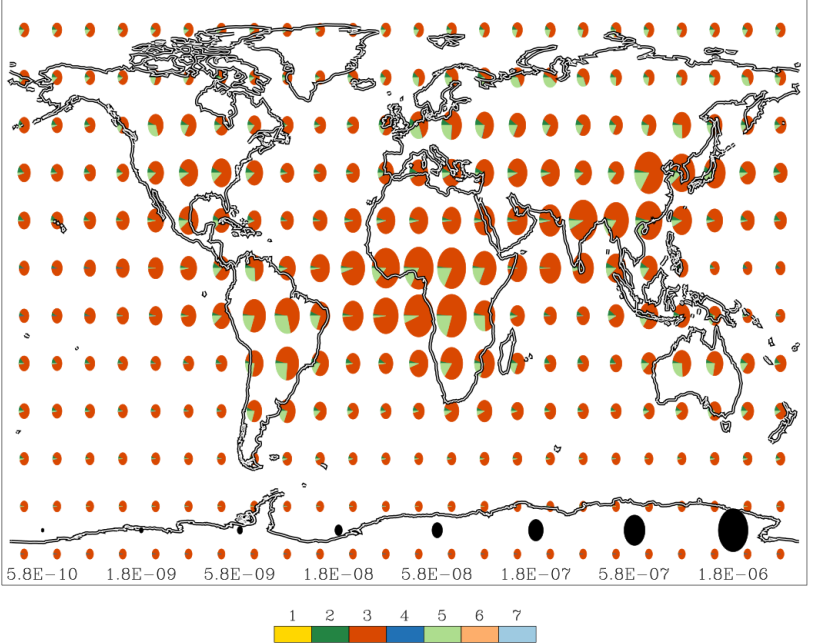

Figure 3. Contributions by different modes to surface $\mathrm{PM}_{2.5}$ and black carbon mass burden for the baseline experiment. The pie chart colors show contribution by mode (see legend below lowest panel), the pie chart's size shows the overall magnitude (legend at the bottom of each panel). From top to bottom: surface $\mathrm{PM}_{2.5}$ (logarithmic scale); black carbon mass burden (logarithmic scale).

coagulation) and $R$ its global removal (through e.g., depositions or coagulation).

The definition of lifetime presupposes that steady-state conditions hold, at least when averaging over suitably long timescales. We checked that the sum of all yearly averaged tendencies for each species per mode indeed resulted in a near-zero value (some discrepancies are expected). Remaining discrepancies are below $1 \%$ for each mode.

Table 3 shows lifetimes for all three experiments and all species and modes involved. For the base-line experiment, we see that the species lifetimes are reasonable and generally agree with other studies (Textor et al., 2006). New are the separate lifetimes for modes and species within a mode. 
Table 3. Lifetimes [days] of all modes and species in ECHAM5.5-HAM2.

\begin{tabular}{|c|c|c|c|c|c|c|c|}
\hline \multirow[t]{2}{*}{ Mode } & \multirow[t]{2}{*}{ Species } & \multicolumn{2}{|c|}{ base-line } & \multicolumn{2}{|c|}{ T31L19 } & \multicolumn{2}{|c|}{ pre-industrial } \\
\hline & & masses & numbers & masses & numbers & masses & numbers \\
\hline & $\mathrm{SO}_{4}$ & 4.6 & & 5.5 & & 5.3 & \\
\hline & POM & 6.0 & & 5.0 & & 5.7 & \\
\hline & $\boldsymbol{\square} \mathrm{BC}$ & 6.1 & & 6.0 & & 7.8 & \\
\hline & $\mathbf{s S}$ & 0.6 & & 0.5 & & 0.6 & \\
\hline & $\square \mathrm{DU}$ & 4.8 & & 4.2 & & 5.0 & \\
\hline 1: nucleation & $\mathrm{SO}_{4}$ & 0.5 & 0.2 & 0.4 & 0.2 & 0.6 & 0.2 \\
\hline \multirow[t]{4}{*}{ 2: Aitken (hydrophilic) } & & 1.0 & 4.7 & 1.1 & 4.9 & 1.8 & 5.6 \\
\hline & $\mathrm{SO}_{4}$ & 3.5 & & 3.3 & & 4.4 & \\
\hline & POM & 0.2 & & 0.2 & & 0.4 & \\
\hline & $\mathrm{BC}$ & 0.4 & & 0.5 & & 0.8 & \\
\hline \multirow[t]{6}{*}{ 3: accumulation (hydrophilic) } & & 3.9 & 6.2 & 4.0 & 6.7 & 3.5 & 6.8 \\
\hline & $\mathrm{SO}_{4}$ & 4.4 & & 5.1 & & 4.9 & \\
\hline & POM & 6.0 & & 5.1 & & 5.4 & \\
\hline & $\mathrm{BC}$ & 6.0 & & 6.0 & & 7.4 & \\
\hline & SS & 1.7 & & 1.3 & & 1.7 & \\
\hline & DU & 7.6 & & 6.7 & & 7.8 & \\
\hline \multirow[t]{6}{*}{ 4: coarse (hydrophilic) } & & 0.9 & 3.4 & 0.8 & 3.1 & 0.8 & 3.2 \\
\hline & $\mathrm{SO}_{4}$ & 2.7 & & 4.0 & & 2.8 & \\
\hline & POM & 2.0 & & 2.1 & & 1.9 & \\
\hline & $\mathrm{BC}$ & 1.9 & & 2.4 & & 2.9 & \\
\hline & SS & 0.6 & & 0.5 & & 0.6 & \\
\hline & DU & 5.1 & & 5.0 & & 5.2 & \\
\hline \multirow[t]{3}{*}{ 5: Aitken (hydrophobic) } & & 0.8 & 0.7 & 0.7 & 0.5 & 1.6 & 1.5 \\
\hline & POM & 0.9 & & 0.7 & & 1.6 & \\
\hline & $\mathrm{BC}$ & 0.7 & & 0.6 & & 1.5 & \\
\hline 6: accumulation (hydrophobic) & DU & 2.2 & 2.2 & 1.7 & 1.8 & 3.3 & 3.4 \\
\hline 7: coarse (hydrophobic) & DU & 2.3 & 3.3 & 1.7 & 2.7 & 3.0 & 4.6 \\
\hline
\end{tabular}

We see that the nucleation mode has a short lifetime of less than half a day. The lifetime for numbers is even much shorter because intra-coagulation (an important process for the nucleation mode as we will later see) affects number densities but not mass densities.

The Aitken mode also has relatively short lifetimes, especially for POM and $\mathrm{BC}$ in the hydrophilic mode. These species are quickly processed into the hydrophilic accumulation mode as we will later see. The lifetime of $\mathrm{SO}_{4}$ is substantially larger than that of POM and BC, the result of a different vertical distribution. The carbons are mostly found in the boundary layer and lower troposphere, but the sulfate mostly in the free troposphere. The number lifetime of hydrophilic Aitken is much larger than its mass lifetime. This is again the result of the vertical distribution, where many small Aitken (sulfate-dominated) particles are found high up in the atmosphere while the hydrophilic Aitken mass is more concentrated in the lower troposphere.

As expected, the hydrophilic accumulation has the largest lifetime. This is after all where aerosol accumulates. Lifetimes for the $\mathrm{SO}_{4}$, POM and $\mathrm{BC}$ species are consequently determined by their lifetimes in the hydrophilic accumulation mode. However, this is not the case for the dust and sea salt species that have the majority of their emissions in the coarse mode. All lifetimes in the hydrophilic coarse mode are smaller than in the hydrophilic accumulation mode.

For the T31L19 experiment, we see that lifetimes agree more-or-less with the baseline experiment. Largest differences are found for the large hydrophobic dust modes (accumulation and coarse), sea salt in the hydrophilic accumulation mode and sulfate in the hydrophilic coarse mode. Lifetimes of the nucleation and Aitken modes that are strongly affected by coagulation are surprisingly robust.

When using the pre-industrial emissions, what stands out is the sensitivity of those lifetimes that are influenced by the condensation of $\mathrm{H}_{2} \mathrm{SO}_{4}$ gas, which itself is the result of conversion of $\mathrm{SO}_{2}$. We can expect aging to happen slower in the pre-industrial climate than in the present day (see also (Stier et al., 2006a)). Indeed, lifetimes for the hydrophobic modes are up to a factor of 2 larger for pre-industrial emissions. In contrast, the lifetimes of natural aerosol in the hydrophilic accumulation and coarse modes (dust and sea salt) hardly change.

\subsection{Global pathways through HAM}

In this section, we analyze the global pathways of aerosol mass and number by studying the net mass and numbers transfer among the modes. 

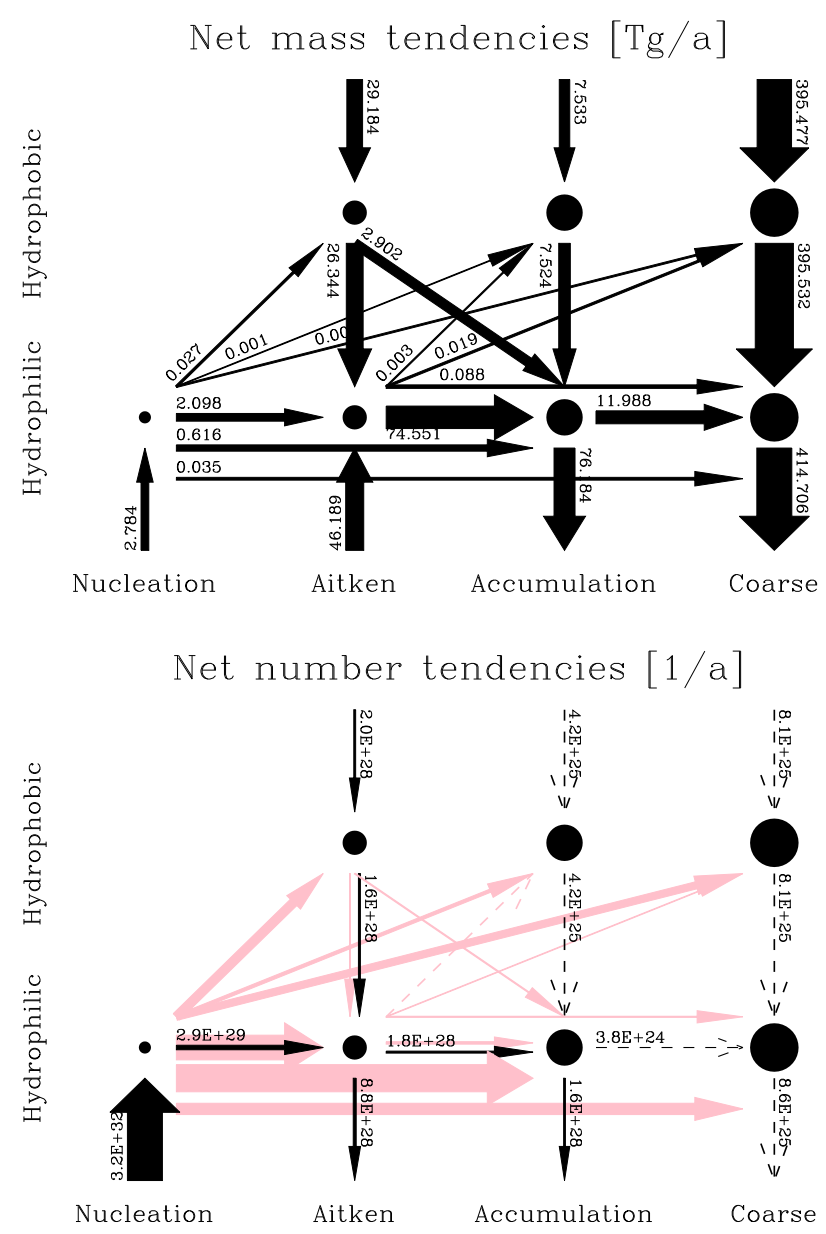

Figure 4. Globally and annually averaged net mass and number tendencies (arrows) between the seven modes (dots) in ECHAM5.5HAM2. The vertical arrows at the top and bottom of the figure represent $\mathrm{H}_{2} \mathrm{SO}_{4}$ nucleation, condensation and production, aerosol primary emission and deposition processes. The arrows between the modes represent coagulation, aging and redistribution processes. Pink arrows are number loss tendencies for coagulation processes. The width of the arrow scales logarithmically with the magnitude of the net tendency. In addition, numerical values for the annual and global averages are given.

The top panel in Fig. 4 shows an annual and global average of net mass tendencies between modes, and between the modes and the rest of the physical environment. Mass enters the aerosol system through the nucleation and Aitken modes as well as through the hydrophobic accumulation and coarse modes. Mass leaves the system through the hydrophilic accumulation and coarse modes. Most mass enters through the hydrophobic coarse mode, followed by the hydrophilic and hydrophobic Aitken mode. This net mass flow hides the fact that a lot of sea salt is emitted and deposited in both the hydrophilic accumulation and coarse modes (for more details see the next section). In contrast to the Aitken and coarse modes, most mass in the hydrophilic accumulation mode has first been processed in other modes.

The bottom panel in Fig. 4 shows a similar graphic but now for an annual and global average of net number tendencies. The pink arrows denote numbers that are lost due to coagulation when smaller particles impact upon larger ones. The picture is very different with most numbers entering through the nucleation mode and the large majority being captured by existing larger particles. Only a small fraction of nucleation particles eventually grows into hydrophilic Aitken particles but it is a very significant amount compared to other sources. Similarly, most hydrophilic accumulation mode particles result from the growth of hydrophilic Aitken particles. In contrast, the hydrophilic coarse mode seems almost isolated from the smaller modes.

\subsection{Spatial distribution of processes per mode}

A more detailed analysis of the pathways per mode will now be presented. We will discuss global distributions of each mode and its species composition as well as the processes that increase or reduce mass and numbers of that mode. The starting point for each discussion will be a plot as in Fig. 5.

This plot consists of six panels. The top-left panel shows the global distribution of the mass burdens. The top-right panel shows global fractional tendencies. The remaining four panels show global maps of the gain and loss tendencies for mass and numbers. In each of these panels, pie charts are used to denote the relative contributions of either species (top-left panel) or processes (all other panels). Excepting the top-right panel, the radii of the pie charts show the burden or total tendency using a logarithmic scaling as indicated in the legend at the bottom of each panel. Number burdens correlate fairly well with masses and are not shown. Although our baseline ECHAM5.5-HAM2 simulation was done at T63L31, results have been averaged over $64(=8 \times 8)$ grid boxes for graphical clarity. Note that the top-left global map uses a different color coding (see Table 3 ) than the other panels (see Table 2).

\subsubsection{The nucleation mode}

The global distribution (5a) of this mode shows a marked latitudinal variation but is otherwise quite homogeneous (using a linear scale for mass densities reveals higher masses near $\mathrm{SO}_{2}$ sources). The nucleation mode is created through nucleation and subsequent condensation of $\mathrm{SO}_{4}$ gas molecules and depleted through capture by larger particles or redistribution to the hydrophilic Aitken mode (Fig 5b). Intra-modal coagulation is an important process due to the large number densities in the upper troposphere-lower stratosphere (see also Fig. 6). In Sect. 4.2, we pointed out the significant difference in lifetime estimates derived from either mass or number tendencies. This discrepancy is explained by intra-modal coagulation that depletes numbers but leaves masses intact. Par- 


\section{Nucleation mode}
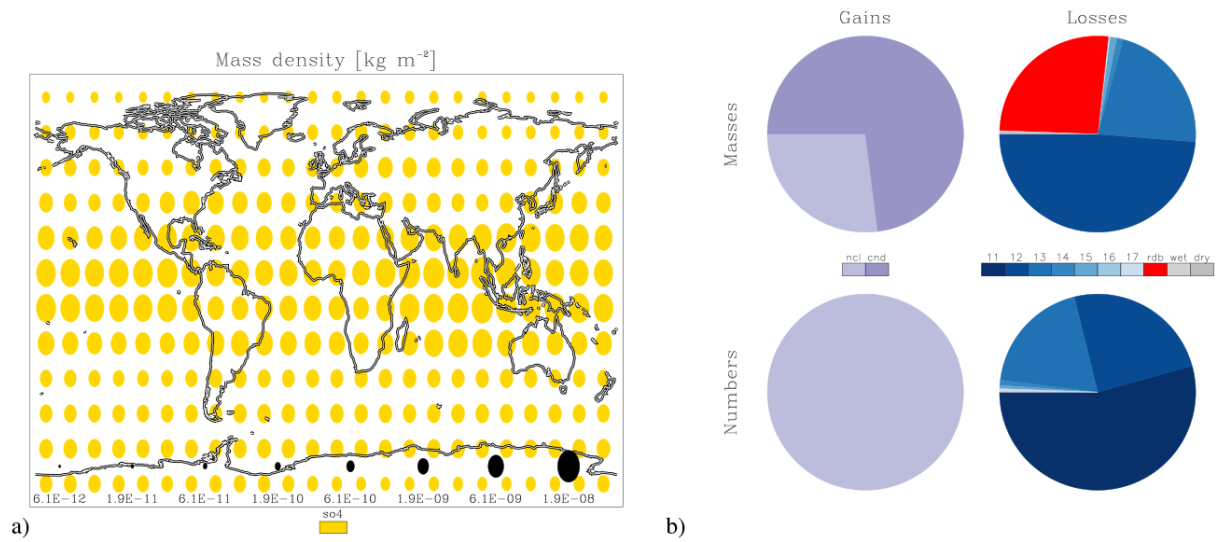

a)

mass gain $\left[\mathrm{kg} \mathrm{m}^{-2} \mathrm{~s}^{-1}\right]$

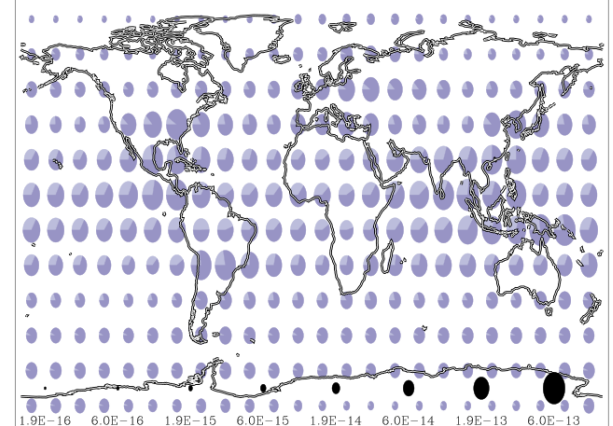

c)

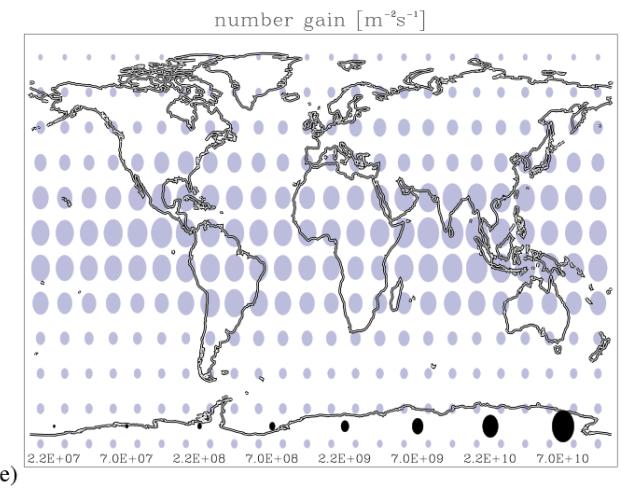

b)

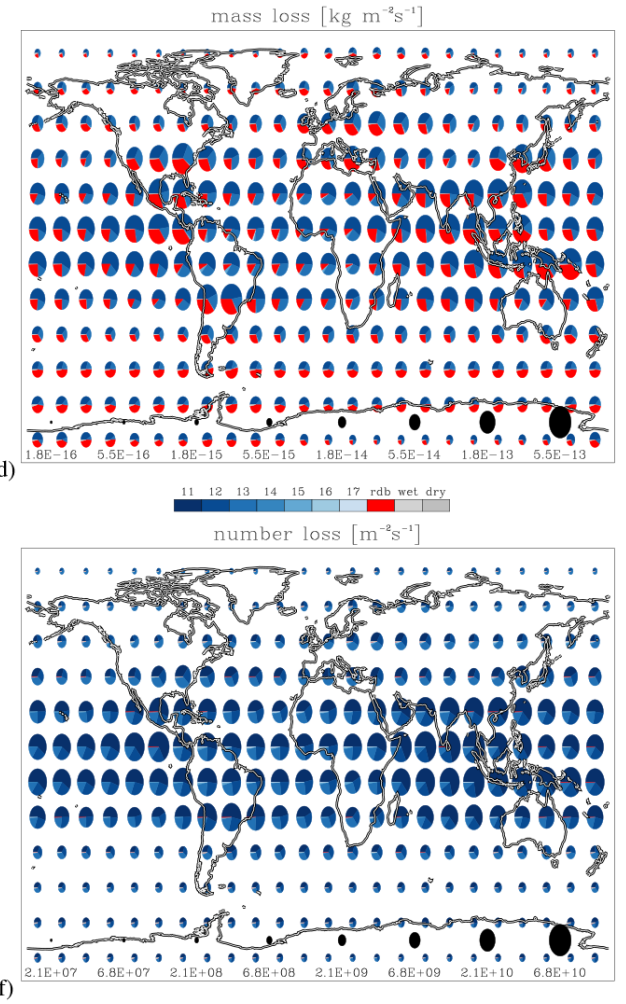

Figure 5. Global distribution of annual burdens (a) and tendencies (b, c, d, e and $\mathbf{f}$ ) of the nucleation mode. The colors indicate either species (defined in Table 3) or processes (defined in Table 2). The pie chart shows fractional contributions, while the radius of the pie indicates total column burden or total column tendency (logarithmic scale as shown in black at the bottom of panels a, $\mathbf{c}, \mathbf{d ,}, \mathbf{e}$ and f). Panel b shows a global average of the tendencies.

ticle growth due to condensation will eventually lead to redistribution ( $5 \mathrm{c}$ and $\mathrm{d}$ ) (the absolute mass tendencies due to condensation and redistribution are correlated). Finally, we note that coagulation of nucleation mode particles with hydrophilic coarse mode or the hydrophobic modes represents negligible loss terms. Neither are wet and dry deposition important for the nucleation mode as the majority of particles are so high up in the atmosphere.

Figure 6 reveals that nucleation occurs mainly near the top of the troposphere. Below the layer, mass gain due to conden- sation dominates. Within the layer, coagulation is responsible for most mass loss, while below it redistribution to the hydrophilic Aitken mode is more important.

Regionally, nucleation and condensation show a very distinct annual cycle due to solar insolation (and the resulting temperature profile in the atmosphere) as shown in Fig. 7 for East Asia. Even so, the fractional tendencies do not vary much, neither for the gain nor for the loss tendencies. This is seen for all regions (see Fig. 1) we have examined although 


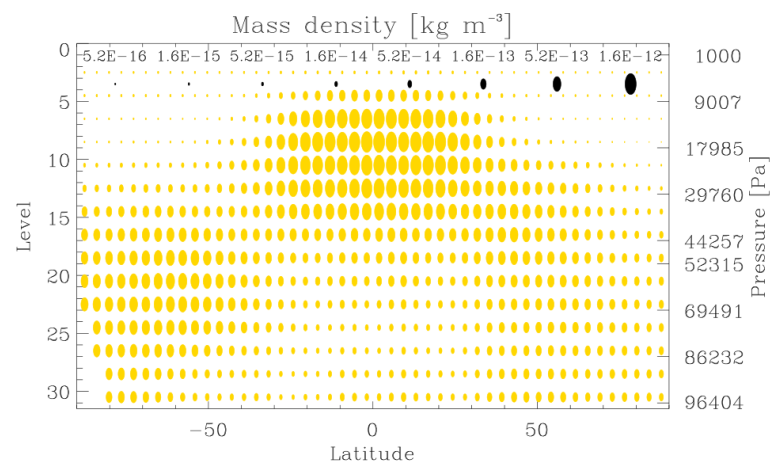

a)
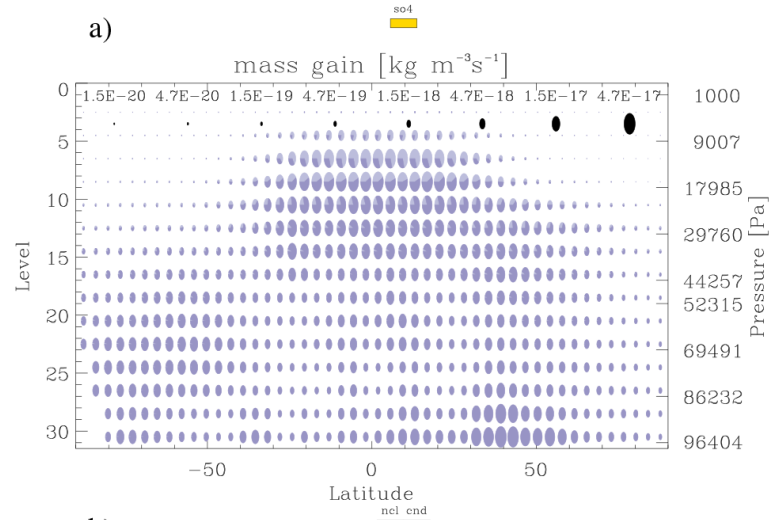

b)
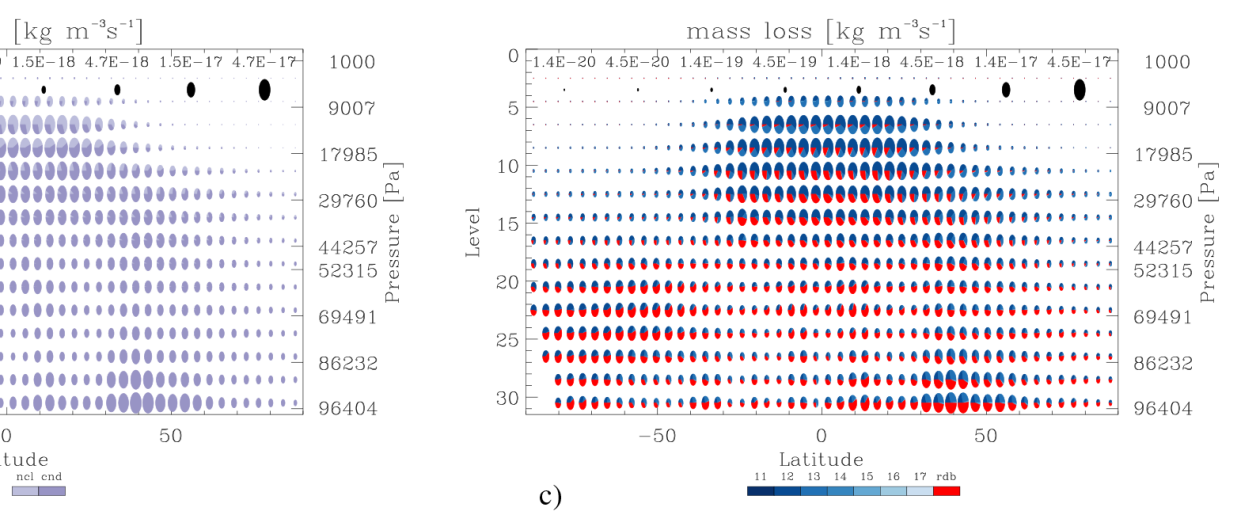

Figure 6. Zonal distribution of annual densities (a) and tendencies (b and c) of the nucleation mode. The colors indicate either species (defined in Table 3) or processes (defined in Table 2). The pie chart shows fractional contributions, while the radius of the pie indicates the zonally averaged density or tendency (logarithmic scale as shown in black at the top of the panels $\mathbf{a}, \mathbf{b}$ and $\mathbf{c}$ ).
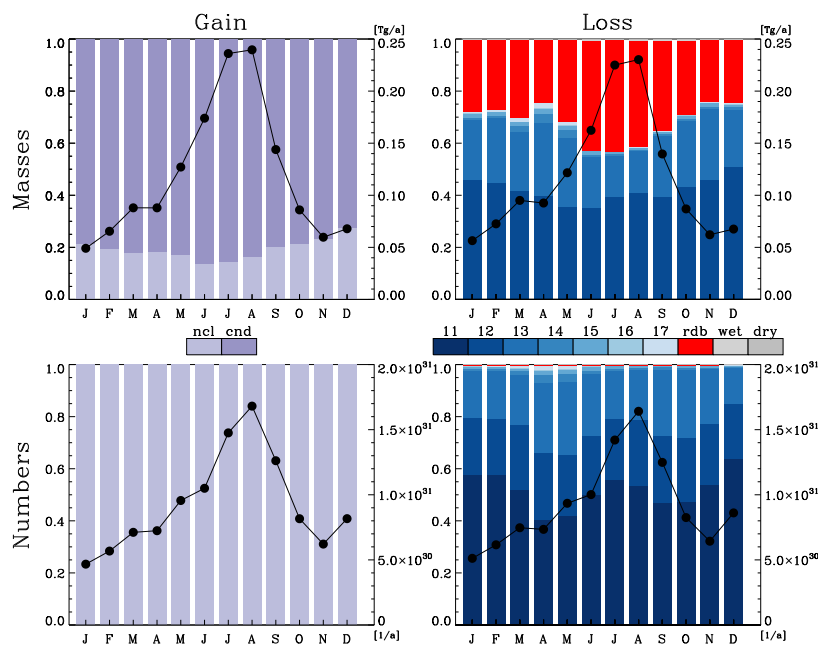

Figure 7. Seasonal cycle of regional tendencies of the nucleation mode over East Asia (see Fig. 1). The colored bars show fractional tendencies (left axis) for the processes defined in Table 2. The solid line (right axis) shows the total tendency.

the relative contribution of condensation and nucleation will differ (see also Fig. 5c).

\subsubsection{The hydrophobic Aitken mode}

The global distribution of the hydrophobic Aitken mode (Fig. 8a) is very distinct and closely related to its emission sources. The hydrophobic Aitken mode is created through primary emission of organic matter and black carbon (Fig. 8b). Actually, mass burdens and mass column tendencies have very similar distributions, a consequence of the short lifetimes (Table 3) of less than a day. The hydrophobic Aitken mode is more or less depleted where it is created (Fig. 8c and d), with conversion into the hydrophilic mode being the major process. This conversion (aging) is accomplished through four pathways: condensation of $\mathrm{H}_{2} \mathrm{SO}_{4}$ (the dominant process) and coagulation of hydrophobic Aitken with either the nucleation, the hydrophilic Aitken or accumulation modes. Although condensation of $\mathrm{H}_{2} \mathrm{SO}_{4}$ adds only a little mass to the hydrophobic Aitken mode (Fig. 8b), it causes a great loss of both mass and numbers. Only a single layer of $\mathrm{H}_{2} \mathrm{SO}_{4}$ is needed in our model to coat hydrophobic Aitken particles and turn them hydrophilic. Coagulation accounts for a bit less than $25 \%$ of the mass and number loss tendencies on a global scale (Fig. 8b), slightly more than the combined deposition processes. Intra-coagulation is a relatively unimportant process. 
Hydrophobic Aitken mode
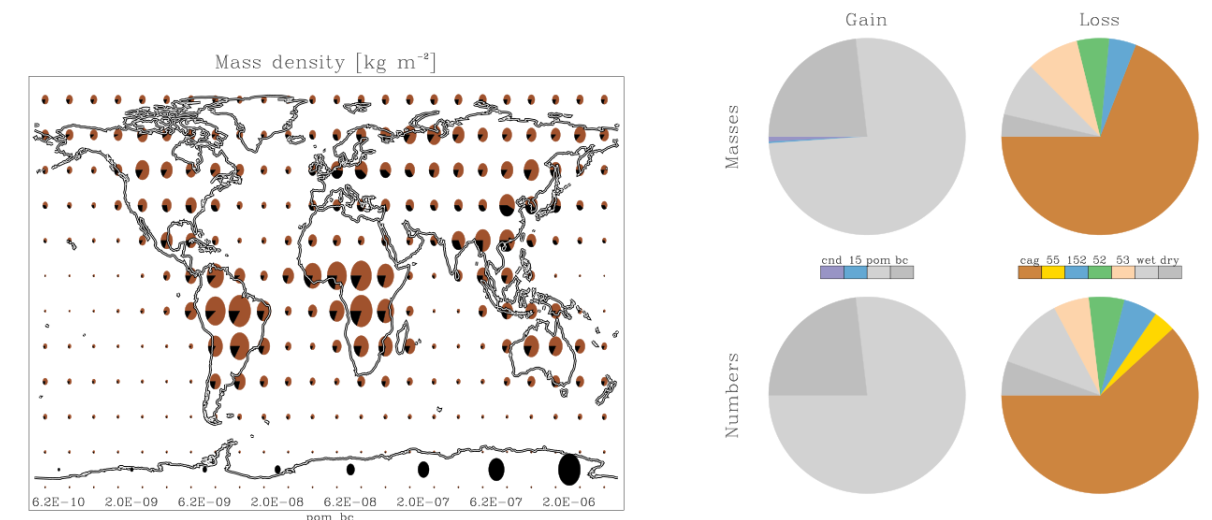

a)

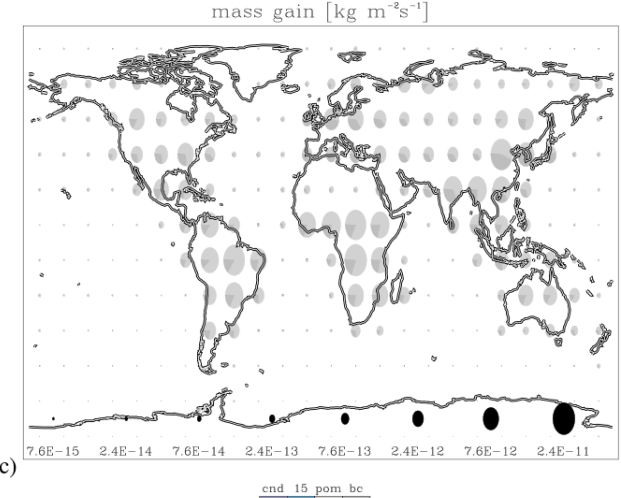

c)

cnd 15 pom be
mber gain $\left[\mathrm{m}^{-2} \mathrm{~S}^{-1}\right]$

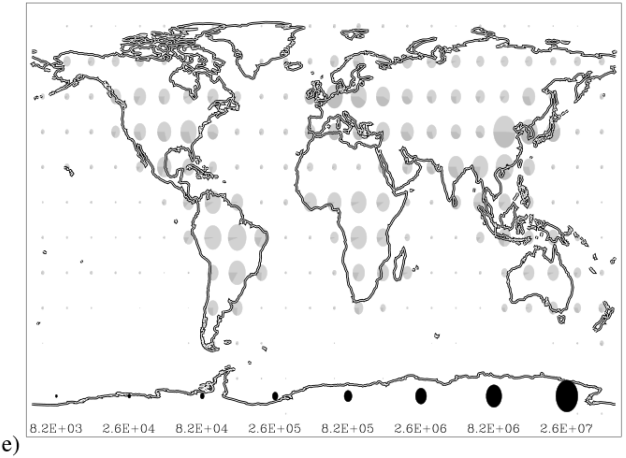

b)

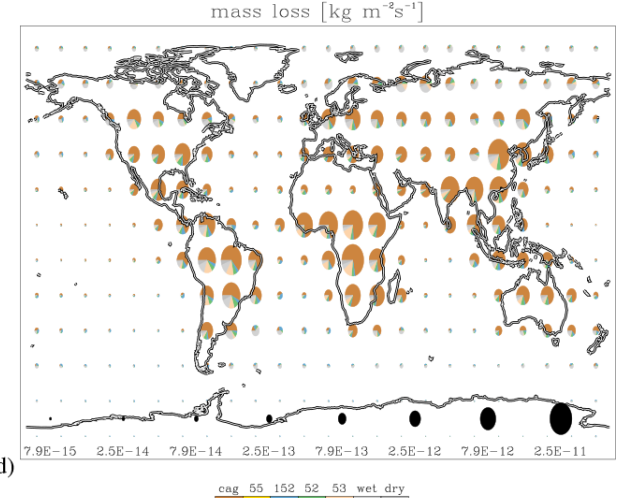
$\begin{array}{llllll}\text { cag } & 55 & 152 & 52 & 53 & \text { wet dry }\end{array}$ number loss $\left[\mathrm{m}^{-2} \mathrm{~s}^{-1}\right]$

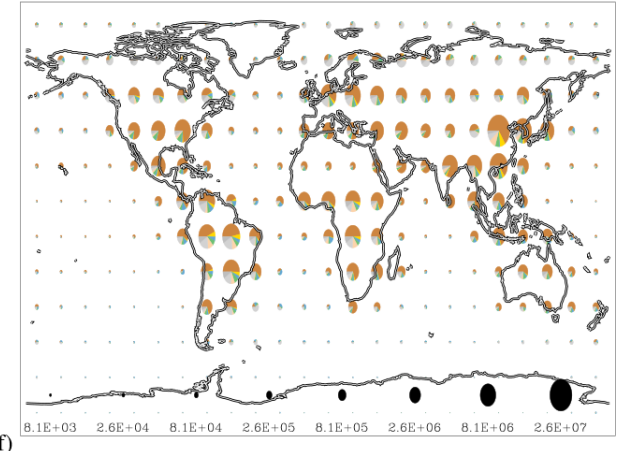

Figure 8. Global distribution of annual burdens (a) and tendencies (b, c, d, e and $\mathbf{f})$ of the hydrophobic Aitken mode. The colors indicate either species (defined in Table 3) or processes (defined in Table 2). The pie chart shows fractional contributions, while the radius of the pie indicates total column burden or total column tendency (logarithmic scale as shown in black at the bottom of panels $\mathbf{a}, \mathbf{c}, \mathbf{d}, \mathbf{e}$ and $\mathbf{f}$ ). Panel $\mathbf{b}$ shows a global average of the tendencies.

There is a marked vertical separation of the aging processes (Fig. 9): coagulation with nucleation particles is important in the nucleation layer, identified previously, and the upper free troposphere, while condensation matters most in the lower troposphere and boundary layer. Both processes coat hydrophobic Aitken particles with a sulfate layer and result in aging as explained in Sect. 2.8.

The typical aging timescale varies greatly with location as a global map shows (Fig. 10). Far away from sulfate sources
(Amazon, Africa), aging timescales are long ( $\sim 2$ days), but near known sites of anthropogenic $\mathrm{SO}_{2}$ sources (e.g., eastern Europe, India, East Asia), aging timescales are short $(\sim 0.3$ days).

\subsubsection{The hydrophilic Aitken mode}

The global distribution of hydrophilic Aitken mass shown in Fig. 11a is fairly homogeneous, although its columnar composition varies. The hydrophilic Aitken mode receives 


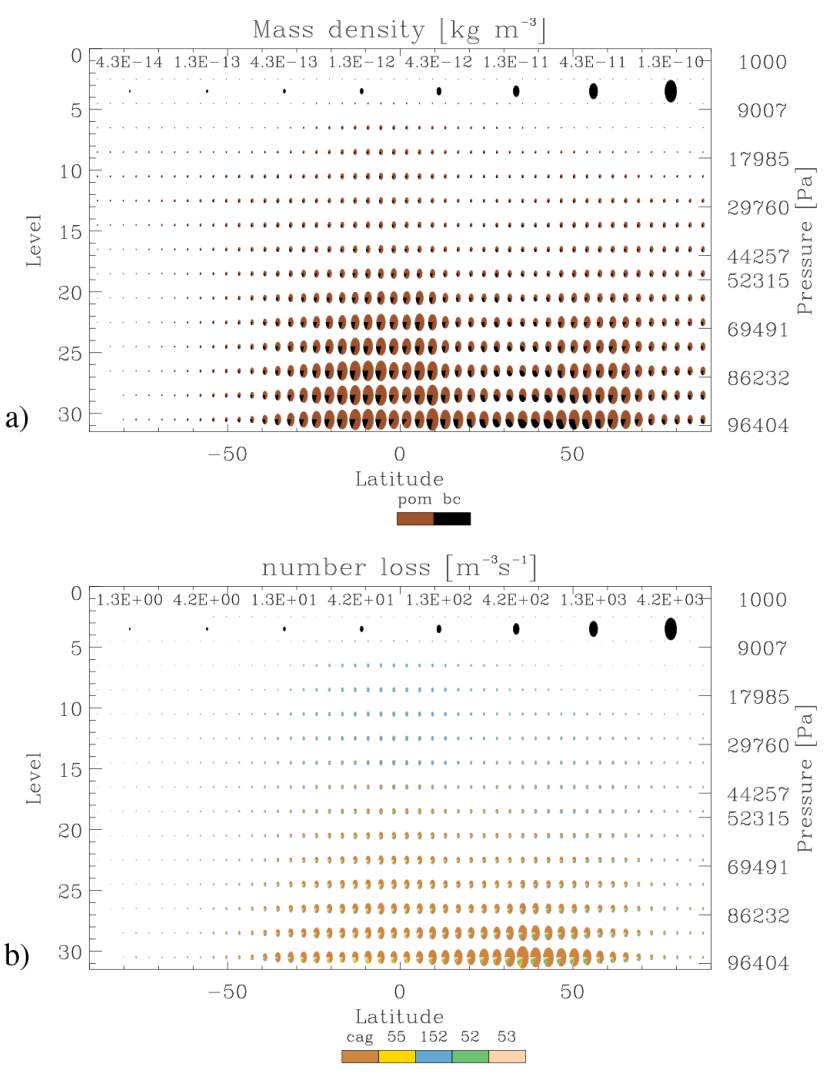

Figure 9. Zonal distribution of annual densities (a) and tendencies (b) of the hydrophobic Aitken mode. The colors indicate either species (defined in Table 3) or processes (defined in Table 2). The pie chart shows fractional contributions, while the radius of the pie indicates the zonally averaged density or tendency (logarithmic scale as shown in black at the top of the panels $\mathbf{a}$ and $\mathbf{b}$ ).

a lot of mass and numbers from other modes, in contrast to the two modes discussed previously. A variety of processes (Fig. 11b) drive its evolution: mass derives from $\mathrm{H}_{2} \mathrm{SO}_{4}$ condensation, aging of hydrophobic Aitken and primary emission of particulate organic matter in fairly equal measures, while numbers come mostly from redistribution from the nucleation mode. The mass tendencies (Fig. 11c and d) show a distinct land-ocean contrast. Over the ocean, $\mathrm{H}_{2} \mathrm{SO}_{4}$ condensation matters most but over land primary emission and aging matter more. Most organic mass derives from hydrophobic Aitken particles aged through $\mathrm{H}_{2} \mathrm{SO}_{4}$ condensation (32\%) and from primary emissions (64\%), while most sulfate mass is the result of $\mathrm{H}_{2} \mathrm{SO}_{4}$ condensation ( $85 \%$, with only $1.5 \%$ due to aged hydrophobic Aitken particles). Black carbon derives entirely from aged hydrophobic Aitken particles.

In contrast, mass loss tendencies are dominated by redistribution to the hydrophilic accumulation mode (Fig. 11b), with deposition being more important over the ocean and at higher latitudes (Fig. 11d). Number loss tendencies are dominated by coagulation (mostly intra-coagulation) and again deposition (mostly over the ocean and at higher latitudes). Note

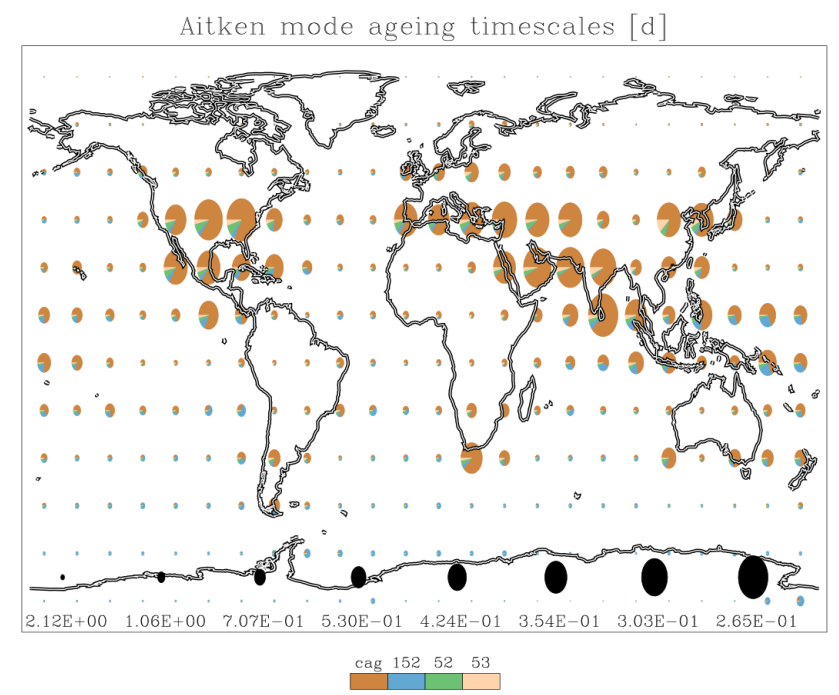

Figure 10. Aging timescales of the hydrophobic Aitken mode. This timescale is defined as $N /\left(\frac{\partial N}{\partial t}\right)$, with $N$ the number density and $\frac{\partial N}{\partial t}$ its time derivative due to aging processes only. The colors indicate processes (Table 2), the radius of the pie indicates the aging timescale (inverse linear scale)

that redistribution to the hydrophilic accumulation mode is an important loss tendency for numbers near primary organic sources. The main process driving particle growth appears to be primary carbon emission and aging of hydrophobic Aitken particles. Both processes introduce relatively large particles into the hydrophilic Aitken mode that will quickly be moved over to the hydrophilic accumulation mode. In contrast, at altitudes where there is a large influx of nucleation (sulfate) particles into the Aitken mode, there is little loss to the accumulation mode. Expressed differently, in the hydrophilic Aitken mode, particles that consist predominantly of sulfate tend to be smaller than particles that predominantly consist of carbons. This affects the redistribution tendency and leads to a significant difference in lifetimes (see Table 3) in the hydrophilic Aitken mode for organic matter and black carbon (0.2-0.4 days) and for sulfate ( 3.5 days). These lifetimes in turn explain why sulfate is so prominent in the global mass distribution (Fig. 11a), while the carbons are more obvious in the mass gain tendencies (Fig. 11c); see also Eq. 5. It should be noted that wet and dry deposition of both sulfate and carbon aerosols in this mode is relatively unimportant.

The seasonal cycle of the fractional tendencies for the hydrophilic Aitken mode is shown for the Savanna region in Fig. 12. In the Savanna, there is a pronounced seasonal cycle of biomass burning emission (also seen in the hydrophobic Aitken mode) that drives the mass tendencies. The fractional mass tendencies are nevertheless rather constant: as emissions increase, the other processes scale up or down (note there is a small increase in the contributions from processes other than primary emission or aging). The number tenden- 
Hydrophilic Aitken mode
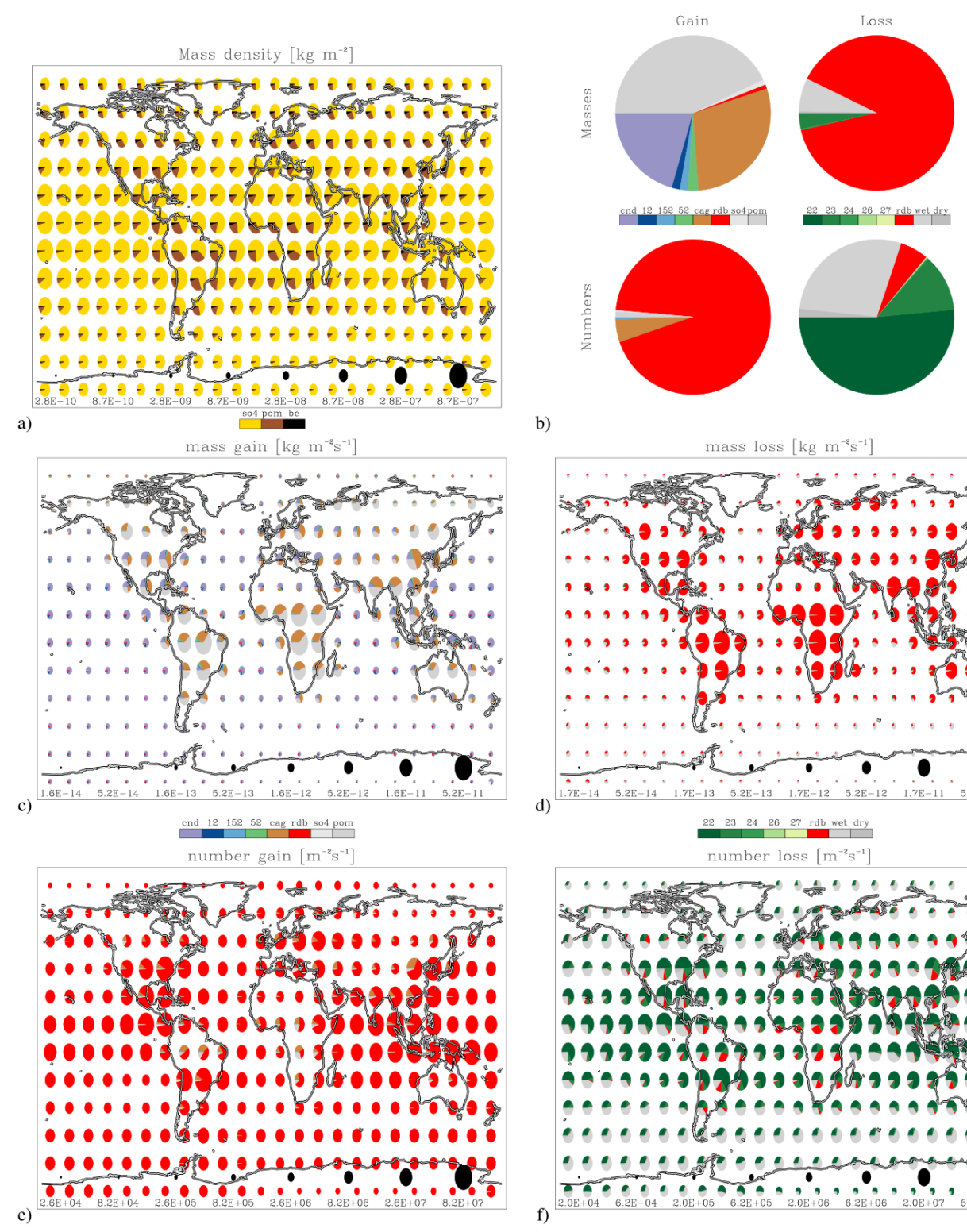

b)

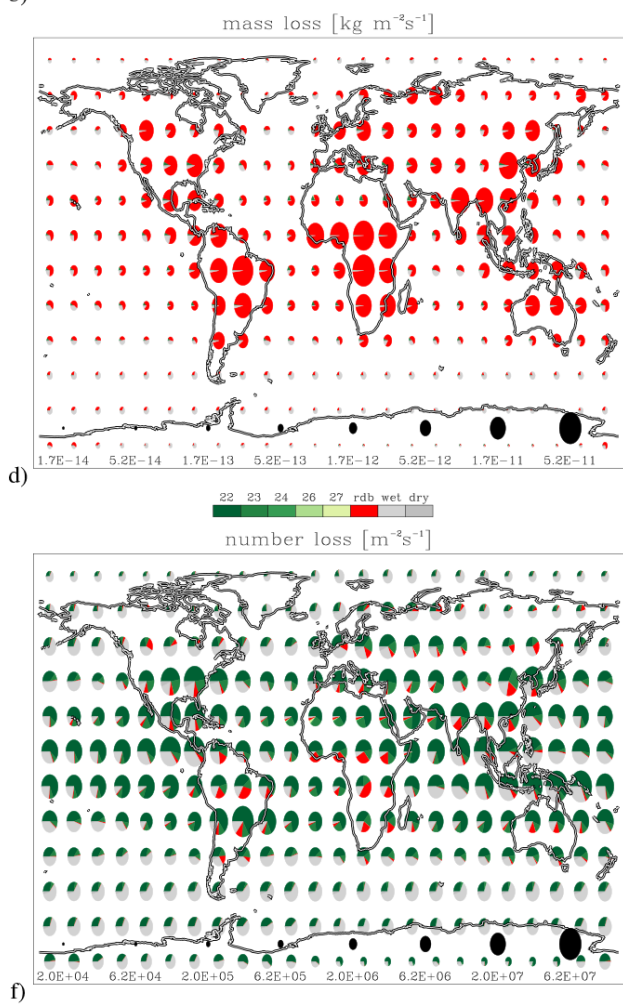

Figure 11. Global distribution of annual burdens (a) and tendencies (b, c, d, e and $\mathbf{f})$ of the hydrophilic Aitken mode. The colors indicate either species (defined in Table 3) or processes (defined in Table 2). The pie chart shows fractional contributions, while the radius of the pie indicates total column burden or total column tendency (logarithmic scale as shown in black at the bottom of panels $\mathbf{a}, \mathbf{c}, \mathbf{d}, \mathbf{e}$ and $\mathbf{f}$ ). Panel $\mathbf{b}$ shows a global average of the tendencies.

cies show quite different behavior, as they are to a large extent dependent on the evolution of the nucleation mode. A similar behavior (strong seasonal cycle in the mass tendencies, but fairly constant fractional mass tendencies) can be seen for the Amazon (not shown).

In contrast, East Asia shows a seasonal cycle where both absolute and fractional mass tendencies vary. Here the cycle is mostly driven by the condensation of $\mathrm{H}_{2} \mathrm{SO}_{4}$ (the emission varies as well but not as much). The fractional mass tendency for $\mathrm{H}_{2} \mathrm{SO}_{4}$ condensation shows a similar cycle as the total mass tendency. The same seasonal cycle in $\mathrm{H}_{2} \mathrm{SO}_{4}$ condensation can be seen for the nucleation, accumulation and coarse modes. The growth of nucleation particles due to condensation results in increased redistribution to hydrophilic Aitken, causing a very similar cycle for the number tendencies as for the mass tendencies in hydrophilic Aitken. Similar behavior can be seen over Europe (not shown). 

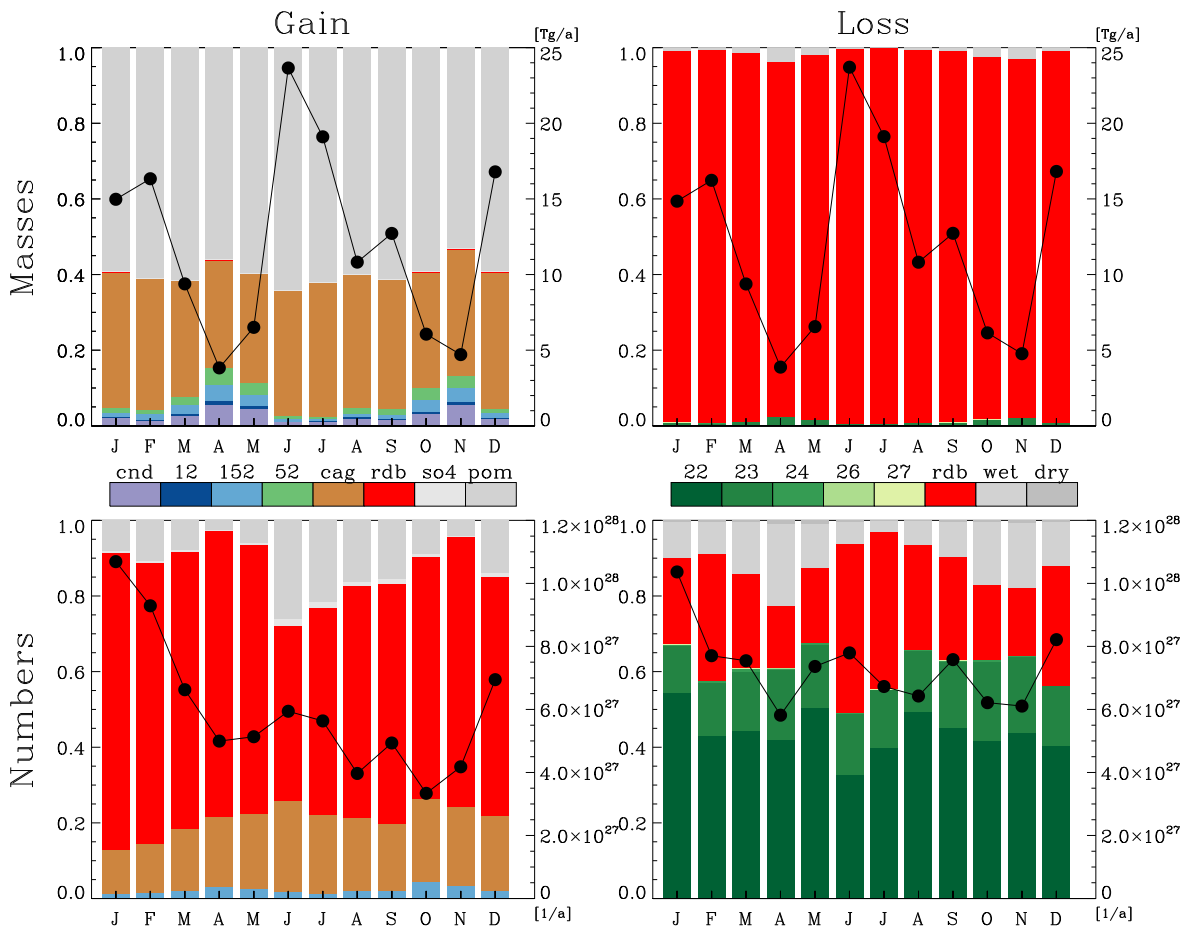

Figure 12. Seasonal cycle of regional tendencies of the hydrophilic Aitken mode over the Savanna (see Fig. 1). The colored bars show fractional tendencies (left axis) for the processes defined in Table 2. The solid line (right axis) shows the total tendency.
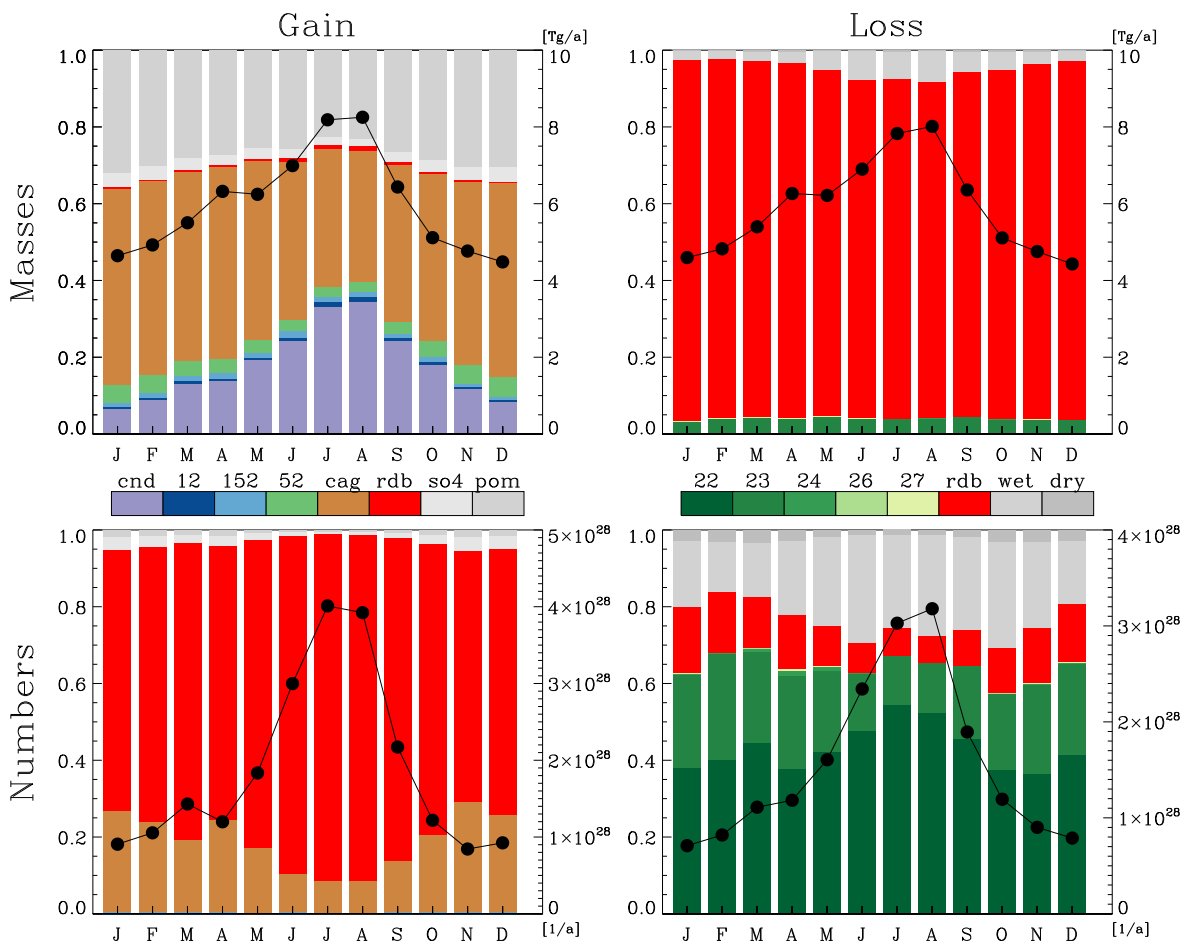

Figure 13. Seasonal cycle of regional tendencies of the hydrophilic Aitken mode over East Asia (see Fig. 1). The colored bars show fractional tendencies (left axis) for the processes defined in Table 2. The solid line (right axis) shows the total tendency. 
Hydrophobic accumulation mode
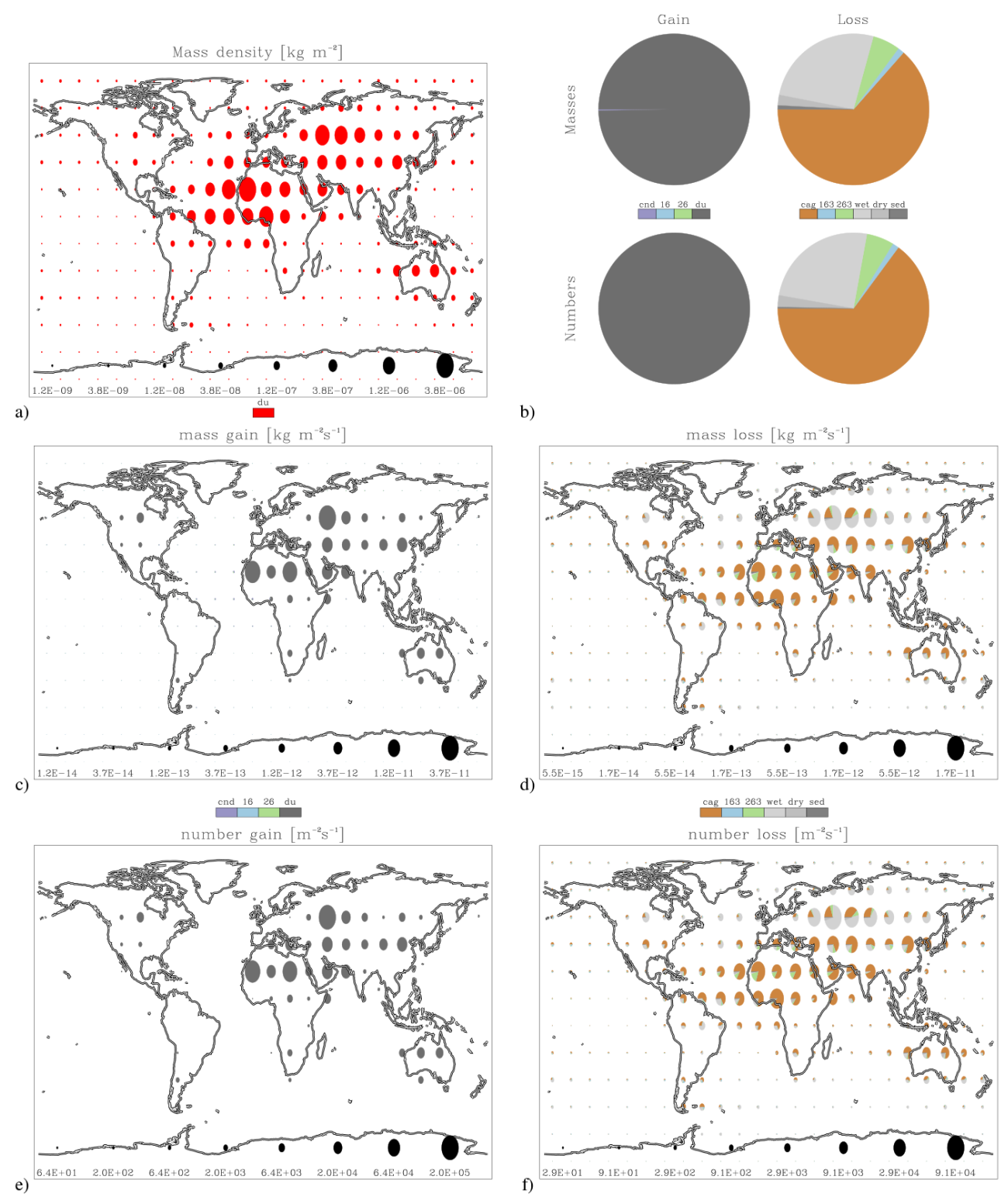

Figure 14. Global distribution of annual burdens (a) and tendencies (b, $\mathbf{c}, \mathbf{d}, \mathbf{e}$ and $\mathbf{f}$ ) of the hydrophobic accumulation mode. The colors indicate either species (defined in Table 3) or processes (defined in Table 2). The pie chart shows fractional contributions, while the radius of the pie indicates total column burden or total column tendency (logarithmic scale as shown in black at the bottom of panels $\mathbf{a}, \mathbf{c}, \mathbf{d}, \mathbf{e}$ and $\mathbf{f}$ ). Panel b shows a global average of the tendencies.

\subsubsection{The hydrophobic accumulation mode}

The hydrophobic accumulation mode is due to the emission of dust particles (Fig. 14b). As a consequence, it is found mainly near deserts (Fig. 14a), although low levels of hydrophobic dust can be found throughout the atmosphere. As with the hydrophobic Aitken mode, mass tendencies and distributions are closely linked (14a, c and d), although the dust lifetime is longer than that of hydrophobic Aitken, (Table 3), and outflows are more conspicuous.
The main loss process for hydrophobic accumulation is aging (conversion to hydrophilic material) through either $\mathrm{H}_{2} \mathrm{SO}_{4}$ condensation (the dominant process) or coagulation with smaller hydrophilic modes (nucleation and Aitken). Regionally, strong differences may exist: over a significant part of Eurasia, wet deposition is actually the dominant loss pathway for hydrophobic accumulation. Note that significant aging occurs in the outflows over the ocean, west of northern Africa and west of Australia. 
Hydrophilic accumulation mode
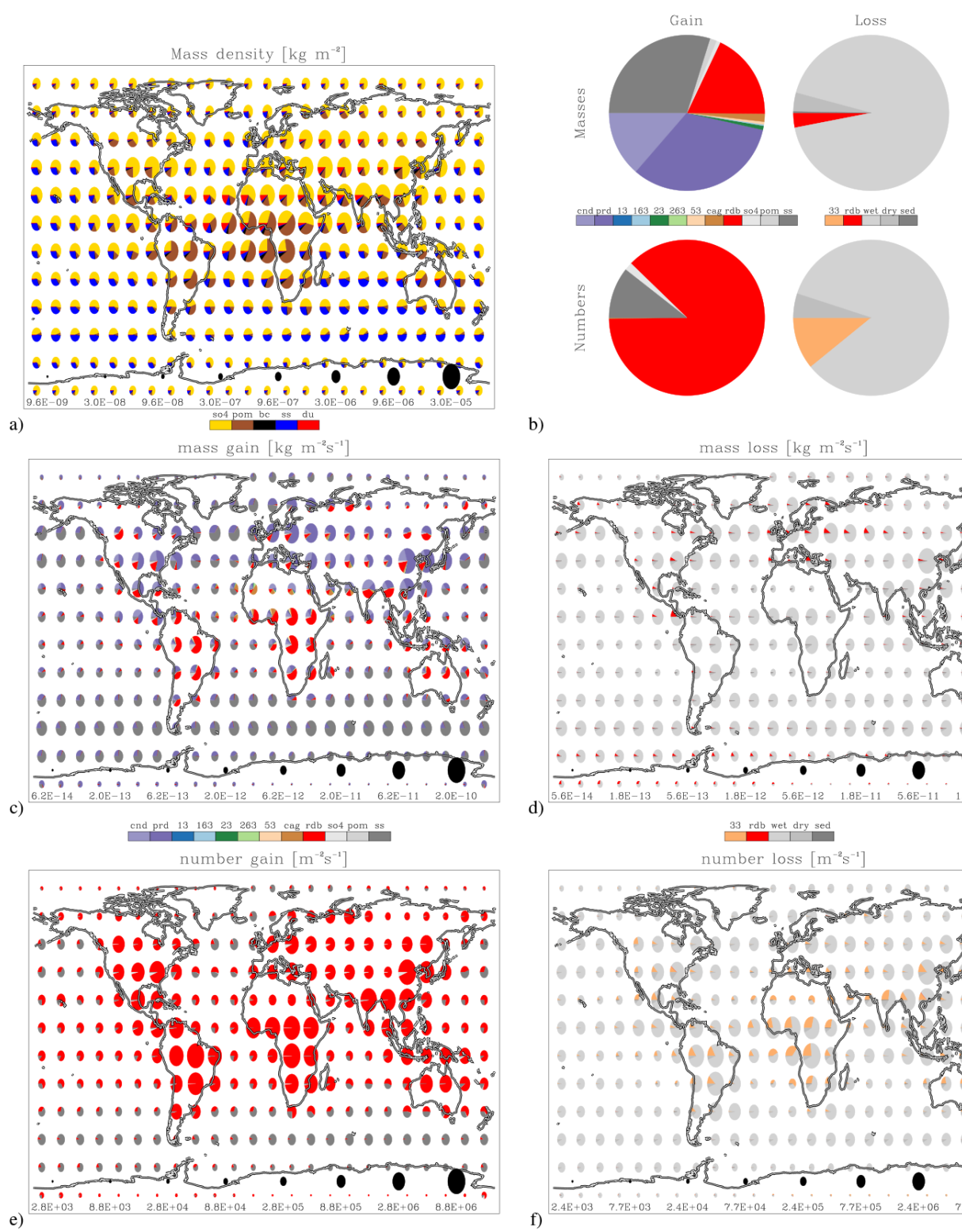

b)
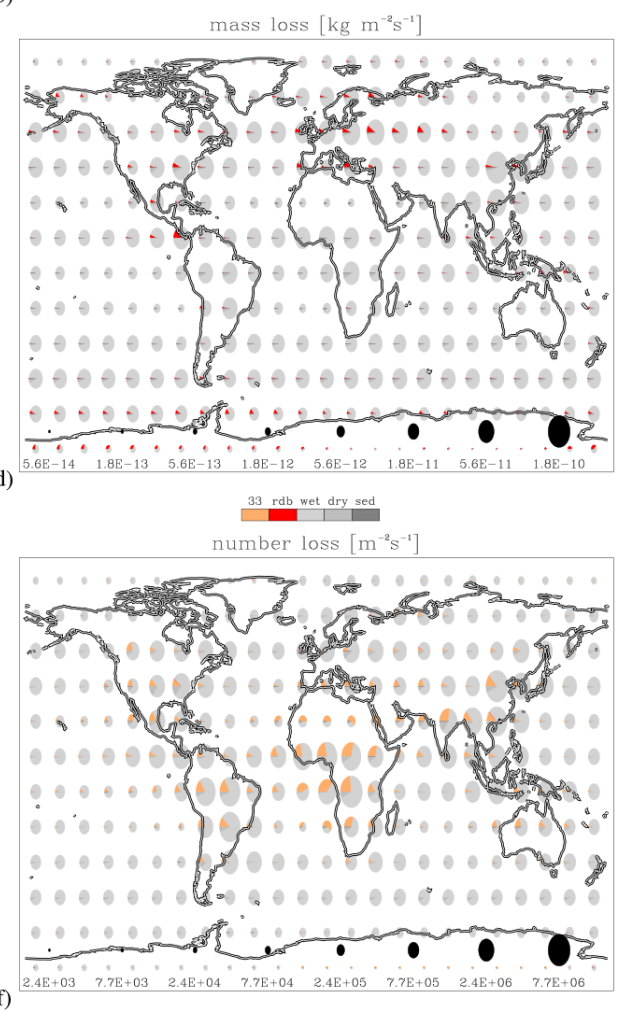

Figure 15. Global distribution of annual burdens (a) and tendencies (b, c, d, e and $\mathbf{f}$ ) of the hydrophilic accumulation mode. The colors indicate either species (defined in Table 3) or processes (defined in Table 2). The pie chart shows fractional contributions, while the radius of the pie indicates total column burden or total column tendency (logarithmic scale as shown in black at the bottom of panels $\mathbf{a}, \mathbf{c}, \mathbf{d}, \mathbf{e}$ and $\mathbf{f}$ ). Panel $\mathbf{b}$ shows a global average of the tendencies.

The hydrophobic accumulation mode contributes relatively little to overall mass of dust in the air. A more detailed description of what happens to hydrophobic dust will be postponed until the discussion of the hydrophobic coarse mode.

\subsubsection{The hydrophilic accumulation mode}

Of the hydrophilic modes discussed so far, the accumulation mode has the least homogeneous global distribution
(Fig. 15a). This is a direct consequence of the multiple pathways that add mass and numbers to it (Fig. 15b, c and e). Primary emissions (mostly sea salt), condensation and in-cloud production of $\mathrm{H}_{2} \mathrm{SO}_{4}$ as well as redistribution from the hydrophilic Aitken mode all cause significant mass gains. These processes show very obvious regional patterns (Fig. 15c): sea salt emission dominates in the Southern Ocean, redistribution from hydrophilic Aitken contributes near carbon sources, and on the continents of the industrial 
Northern Hemisphere condensation and in-cloud production of $\mathrm{H}_{2} \mathrm{SO}_{4}$ often dominates.

As with the hydrophilic Aitken mode, there is a distinct difference between mass and number gain tendencies: almost all numbers derive from the hydrophilic Aitken mode, with some contribution from primary emissions. In contrast, loss tendencies are mainly due to wet deposition.

Surprisingly, even near dust sources, aged dust is not the main contributor to the hydrophilic accumulation mode. This can be seen in both the accumulation density and tendency maps.

The variety of sources for hydrophilic accumulation matter also leads to a colorful picture of the vertical distribution of species compositions; see Fig. 16. Almost everywhere sulfate is the major ingredient (masswise) of aerosol, except in the lower atmosphere over the Southern Ocean where sea salt dominates. With very few exceptions, hydrophilic accumulation aerosol is always a mixture with at least $\sim 25 \%$ of its mass different from the main constituent.

Different seasonal cycles are present in regional hydrophilic accumulation aerosol; see Figs. 17, 18, and 19. Over the Savanna, the hydrophilic accumulation tendencies are clearly driven by emission of carbons into the Aitken mode (Fig. 12). Unsurprisingly, redistribution is the major gain term for both mass and numbers. Note that the numbers loss process due to intra-coagulation shows a strong seasonal cycle in trend with the gain of mass and numbers. Over East Asia, we see the same cycle in fractional mass tendency for $\mathrm{H}_{2} \mathrm{SO}_{4}$ condensation as we saw for the hydrophilic Aitken mode (Fig. 13). Note that total mass tendency does not change much and so any increase in $\mathrm{H}_{2} \mathrm{SO}_{4}$ condensation is met by a reduction in in-cloud $\mathrm{H}_{2} \mathrm{SO}_{4}$ production. Finally, we have a look at the Southern Ocean (Fig. 19). Although absolute gain tendencies are rather constant, there is an obvious cycle in the fractional tendencies. This cycle is again related to sulfate: mass tendencies are driven by in-cloud production, while number densities are driven by condensation onto and subsequent redistribution of hydrophilic Aitken particles.

\subsubsection{The hydrophobic coarse mode}

Like the hydrophobic accumulation mode, the hydrophobic coarse mode, results from the emission of dust. The coarse particles are of course bigger than the accumulation particles and have significantly more mass, although fewer numbers can be found in this mode than in the accumulation mode. Yet the overall description of densities and tendencies is very similar (Fig. 20).

Aging timescales for the hydrophobic coarse mode can be seen in Fig. 21. These timescales can differ by a factor of $\sim 10$, from 0.8 days to 7 days. Along the main dust belt (northern Africa, Arabian peninsula, Asia) in particular, timescales decrease with longitude as progressively more industrially polluted areas are encountered.

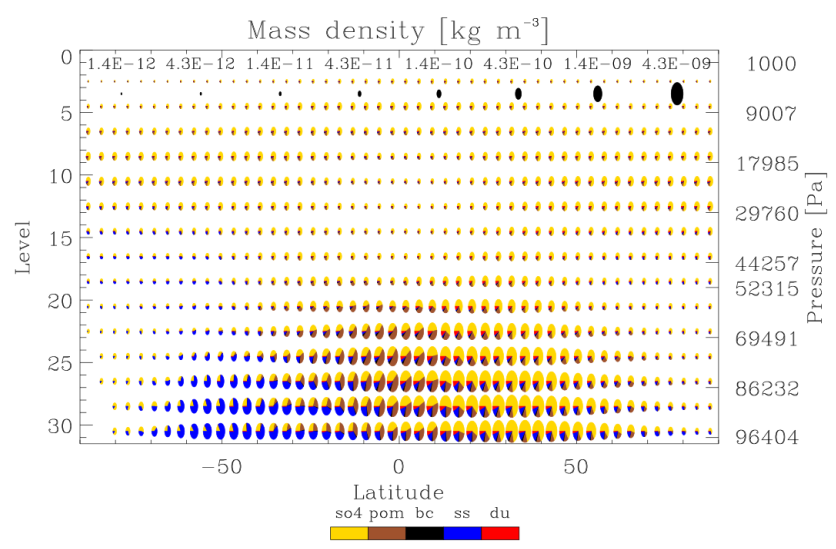

Figure 16. Zonal distribution of annual densities of the hydrophilic accumulation mode. The colors indicate species (defined in Table 3). The pie chart shows fractional contributions, while the radius of the pie indicates the zonally averaged density (logarithmic scale as shown in black at the top).

\subsubsection{The hydrophilic coarse mode}

The hydrophilic coarse mode consists compositionwise mostly of sea salt and dust (Fig. 22a). The sea salt is due to primary emissions while the dust is aged hydrophobic coarse dust (Fig. 22c). Even though various pathways exist that bring in aerosol from smaller modes (growth of hydrophilic accumulation, coagulation) or through other processes (condensation and in-cloud production of $\mathrm{H}_{2} \mathrm{SO}_{4}$ ), these processes hardly matter at all (Fig. 22b). The evolution of the coarse modes is to a large extent decoupled from the other modes.

Dust outflows over the ocean are not very apparent in the hydrophilic accumulation mode (Fig. 15a) but very obvious in the hydrophilic coarse mode (Fig. 22a). More-over, comparing Figs. 20 and 22, it appears that in the Asian outflow most dust is hydrophilic while near Africa and Australia the outflow really is an external mixture of hydrophobic and hydrophilic coarse dust. Asian dust sources are more inland and the dust travels over heavily industrialized regions before flowing out over the ocean, so there is plenty of time for dust to age. Aging times over East Asia are much reduced (Fig. 21).

There are no pathways for the hydrophilic coarse mode loss other than wet and dry deposition and sedimentation, but due to the size of the involved particles and their vertical distribution all three deposition processes play a part in removing this mode from the air.

As the coarse modes are decoupled from the other modes, their seasonal cycle can be quite different. We show the cycle over East Asia as an example; see Fig. 23. Sea salt emission is obviously the most important source of hydrophilic coarse over East Asia. The second major source of hydrophilic coarse matter is aged dust. Note that redistribution from hy- 

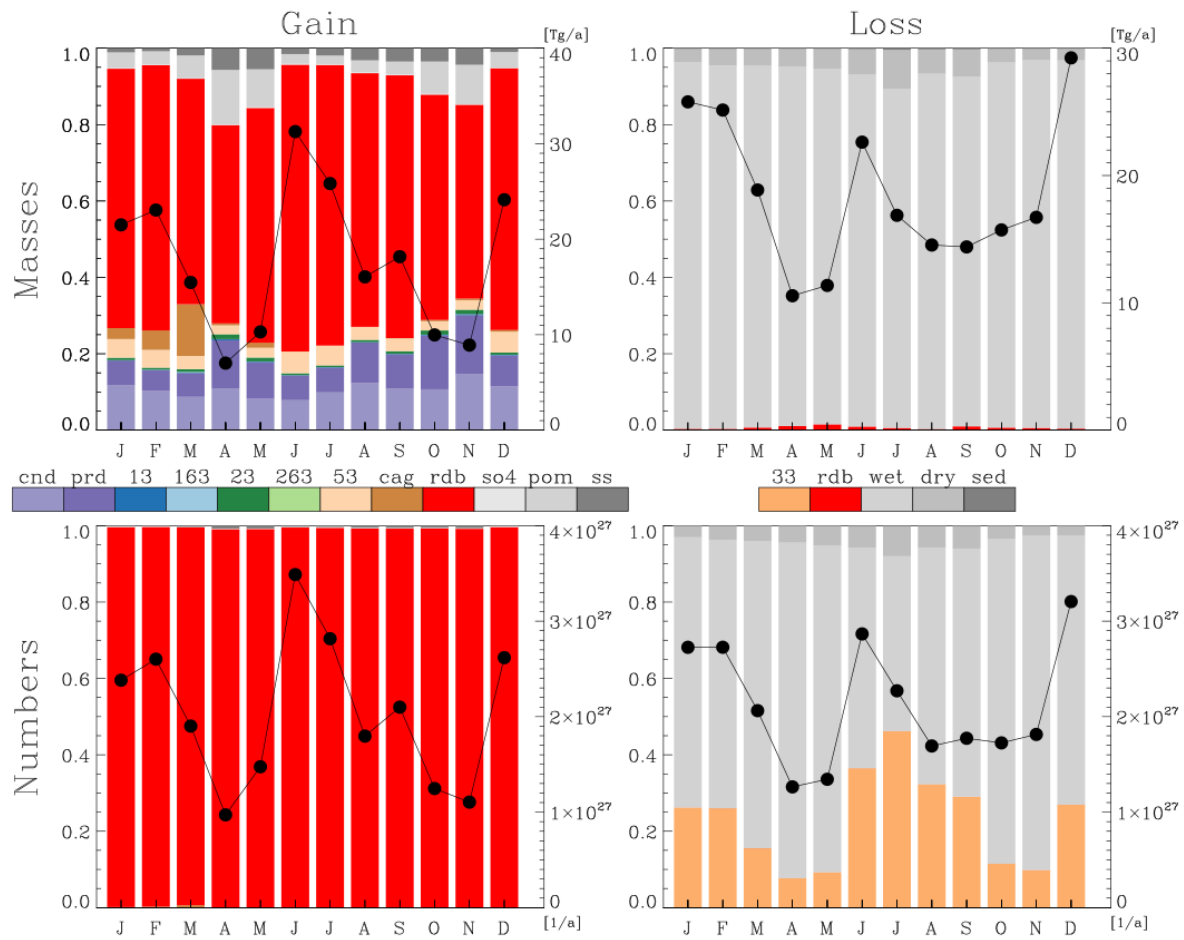

Figure 17. Seasonal cycle of regional tendencies of the hydrophilic accumulation mode over the Savanna (see Fig. 1). The colored bars show fractional tendencies (left axis) for the processes defined in Table 2. The solid line (right axis) shows the total tendency.
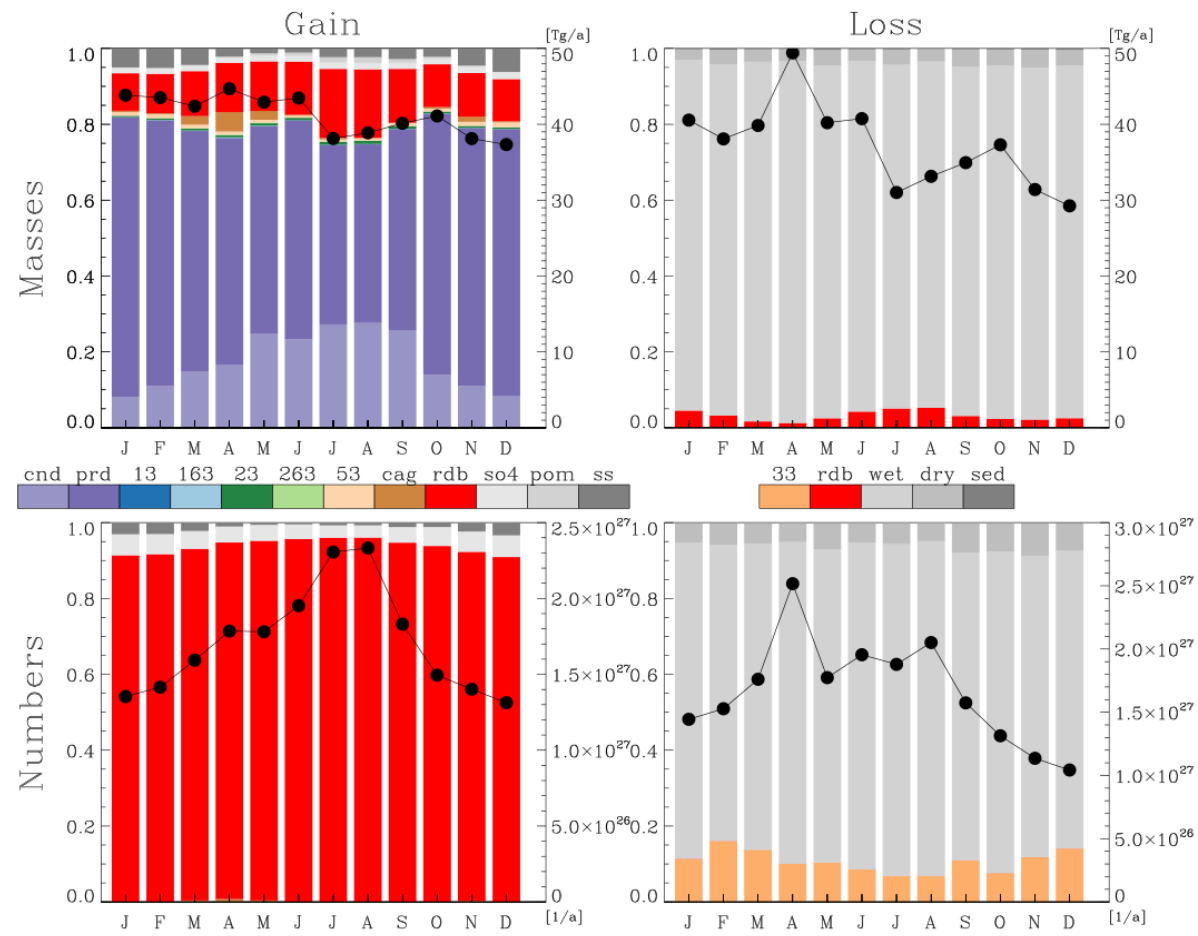

Figure 18. Seasonal cycle of regional tendencies of the hydrophilic accumulation mode over East Asia (see Fig. 1). The colored bars show fractional tendencies (left axis) for the processes defined in Table 2. The solid line (right axis) shows the total tendency. 

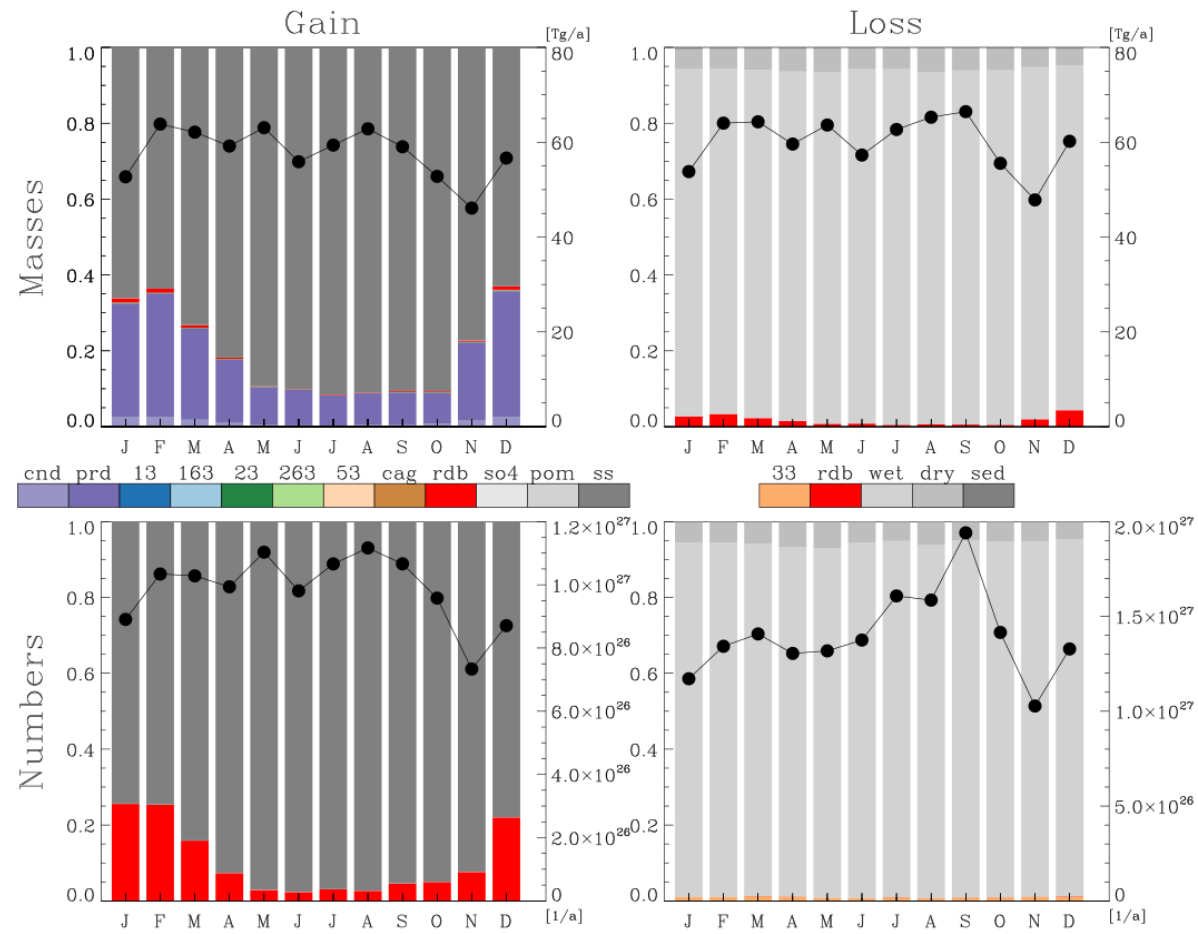

Figure 19. Seasonal cycle of regional tendencies of the hydrophilic accumulation mode over the Southern Ocean (see Fig. 1). The colored bars show fractional tendencies (left axis) for the processes defined in Table 2. The solid line (right axis) shows the total tendency.

drophilic accumulation particles into the coarse mode only contributes when the absolute tendencies are low.

\subsection{Sensitivity studies}

The final part of this analysis concerns the sensitivity of our results to the assumptions in using a grid resolution of T63L31 and present-day emissions. Grid resolution is known to affect dust emissions, nucleation events and removal processes (note that in ECHAM-HAM, the dust emission scheme has been tuned to yield very similar results independent of resolution). Pre-industrial primary emissions of aerosol were less and, in particular, reduced emission of $\mathrm{SO}_{2}$ gas will affect sulfate nucleation and condensation. Especially coagulation, which depends on a product of two number densities, may be sensitive to changes in either resolution or emissions. However, as we will show, the pathway analysis (that is, the fractional tendencies) is (are) not fundamentally affected.

Figure 24 shows regional fractional tendencies for North America (see Fig. 1) of all processes for both masses and numbers at two different grid resolutions, the baseline T63L31 and sensitivity T31L19 experiments. Since these data all lie closely to the $y=x$ line, we conclude that grid resolution has no significant impact on pathways, even though there is a little bit of scatter. Other regions show similar results: Table 4 shows the Spearman rank correlations between the fractional tendencies for the T63L31 and T31L19 experiments. In general they are equal to or above 0.98 suggesting only small differences in the relative contributions of the various processes when resolution changes. The exceptions are the mass gain over the Amazon and the Savanna that show lower correlations. The cause of the lower correlation is the presence of dust emitting regions in the edges of our defined regions (Fig. 1) for the T63L31 experiment and their absence in the T31L19 experiment. As a result, large swings in the relative contributions to mass gain of the hydrophobic accumulation and coarse modes through emission and $\mathrm{SO}_{4}$ condensation exist. This in no way invalidates our previous conclusion and if we exclude the aforementioned processes, correlations for the Amazon and the Savanna are 0.94 and 0.91 , respectively (correlations are even higher when all processes affecting hydrophobic accumulation and coarse particles are excluded). Note that the resolutions used in this paper, which are typical for climate models with interactive aerosol, are not able to resolve typical black carbon plumes as measured by the HIPPO campaigns (Weigum et al., 2012).

Figure 25 shows regional fractional tendencies for North America of all processes for both masses and numbers for either pre-industrial (PI) or present-day (PD) emission scenarios. Consequently, looking at the left panels for mass and number gains, we see that primarily emissions (grey shades), in-cloud production (dark purple) and aging through sulfate condensation (brown) have changed. In particular, the emission of organic matter and black carbon into the hydropho- 
Hydrophobic coarse mode
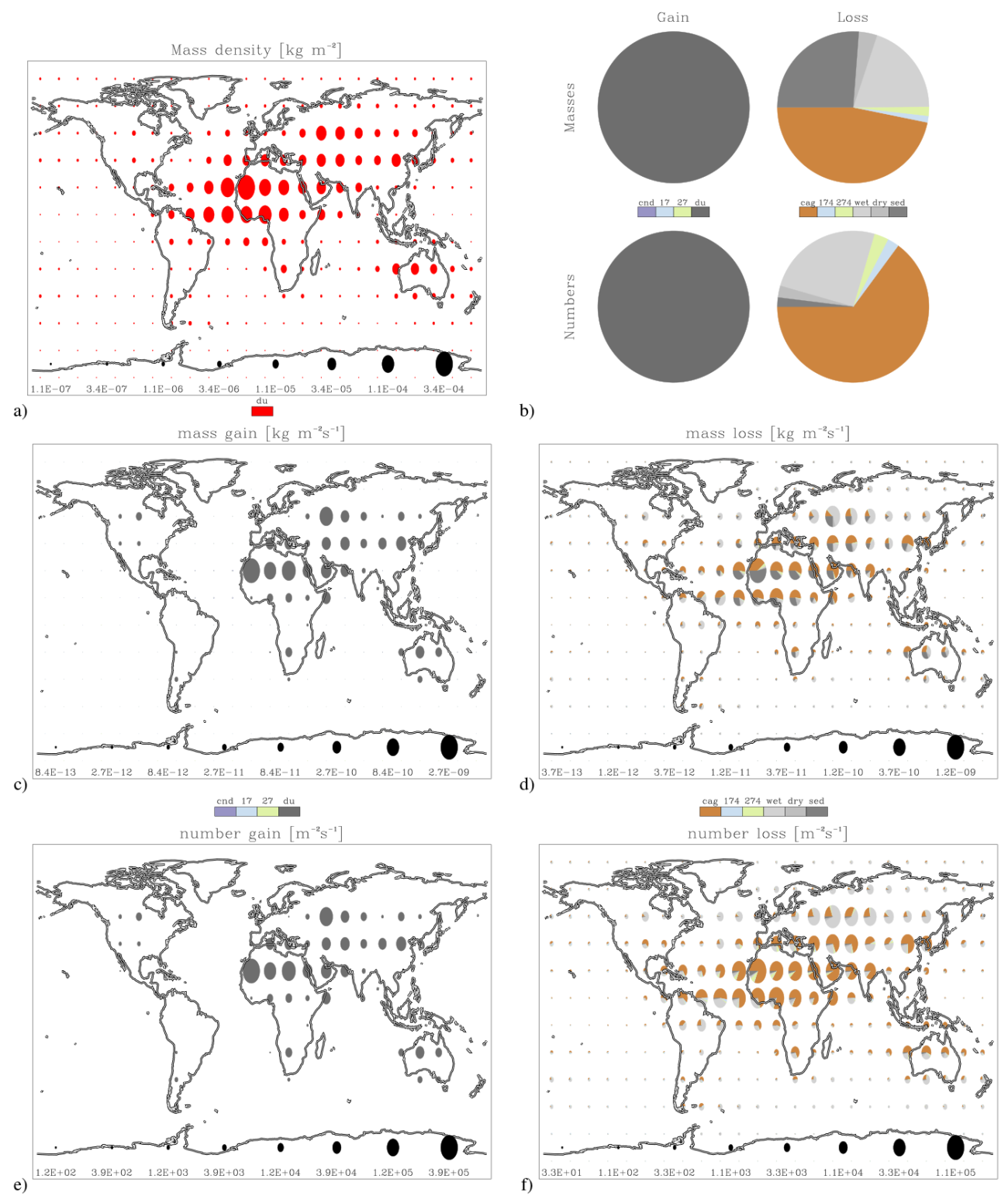

Figure 20. Global distribution of annual burdens (a) and tendencies (b, c, d, e and $\mathbf{f})$ of the hydrophobic coarse mode. The colors indicate either species (defined in Table 3) or processes (defined in Table 2). The pie chart shows fractional contributions, while the radius of the pie indicates total column burden or total column tendency (logarithmic scale as shown in black at the bottom of panels a, $\mathbf{c}, \mathbf{d ,}, \mathbf{e}$ and f). Panel b shows a global average of the tendencies.

bic Aitken changes significantly in its importance for numbers gain. Looking at the right panels for mass and number losses, we see that mostly wet deposition (light grey) of the hydrophobic modes and aging through sulfate condensation (brown) have changed. Under present-day conditions, aging due to sulfate condensation of hydrophobic modes has become more important and this is balanced by a decreased importance of deposition as a loss process of the same hydrophobic modes. It is not that the deposition processes become less effective but rather aging speeds up, resulting in the shorter lifetime of the hydrophobic modes that we already discussed in Sect. 4.2. Other regions show similar results: Table 4 shows the Spearman rank correlations between the fractional tendencies for the PI and PD experiments. North America turns out to be the region with the largest changes in fractional tendencies due to emissions.

Regardless of these changes due to emissions the overall hierarchy of processes remains unaltered. In particular, most data points in Fig. 25 remain within the band $y=x \pm 0.1$ showing there are no substantial changes in pathways. That 
Table 4. Spearman rank correlation of fractional tendencies for different regions and sensitivity experiments

\begin{tabular}{lcccc|cccc}
\hline & \multicolumn{3}{c}{ T31L19 vs T63L31 } & & \multicolumn{3}{c}{ PI vs PD emissions } \\
Region & mass gain & number gain & mass loss & number loss & mass gain & number gain & mass loss & number loss \\
\hline Amazon & 0.70 & 0.99 & 0.98 & 0.99 & 0.99 & 0.97 & 0.99 \\
Arabian peninsula & 0.99 & 1.00 & 0.98 & 0.99 & 0.96 & 0.96 & 0.98 \\
East Asia & 0.99 & 1.00 & 0.99 & 1.00 & 0.95 & 0.94 & 0.95 \\
Europe & 0.98 & 1.00 & 0.99 & 0.99 & 0.92 & 0.92 & 0.97 \\
North America & 1.00 & 1.00 & 0.98 & 0.99 & 0.86 & 0.84 & 0.95 \\
Sahara & 1.00 & 0.99 & 0.98 & 0.99 & 0.99 & 0.96 & 0.99 & 0.94 \\
Savanna & 0.74 & 1.00 & 0.99 & 1.00 & 0.99 & 0.99 & 0.99 \\
Siberia & 0.99 & 0.99 & 0.99 & 0.99 & 0.96 & 0.96 & 0.91 & 0.99 \\
Southern Ocean & 1.00 & 1.00 & 0.99 & 0.99 & 0.99 & 0.97 & 0.99 \\
\hline
\end{tabular}

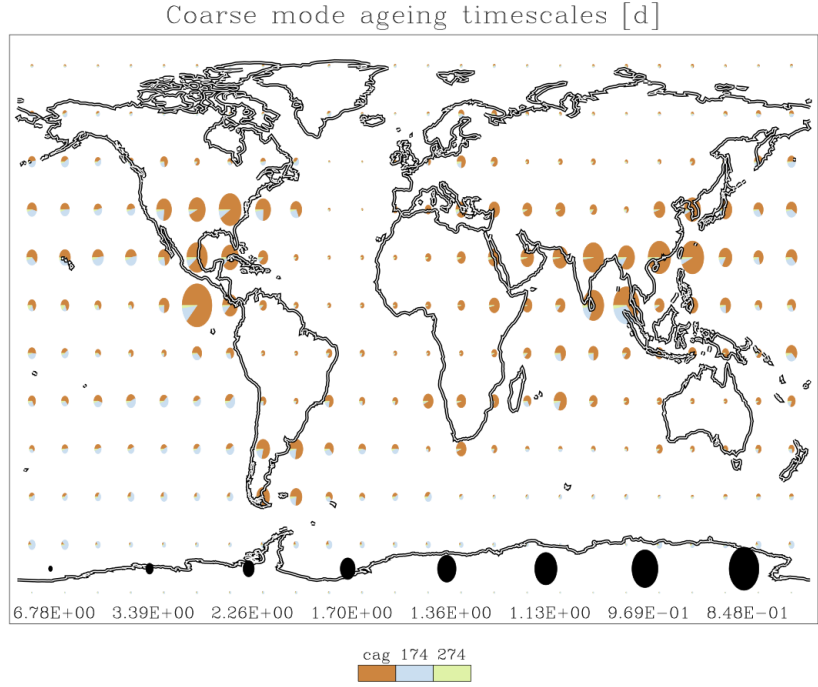

Figure 21. Aging timescales of the hydrophobic coarse mode. This timescale is defined as $N /\left(\frac{\partial N}{\partial t}\right)$, with $N$ the number density and $\frac{\partial N}{\partial t}$ its time derivative due to aging processes only. The colors indicate processes (Table 2), the radius of the pie indicates the aging timescale (inverse linear scale)

is not to say that the absolute tendencies hardly change. In fact, PI tendencies for sulfate condensation are substantially reduced from PD tendencies, but as the aerosol system adjusts fractional tendencies change much less. This is shown in Fig. 26, where ratios of PI to PD tendencies are plotted against ratios of PI to PD fractional tendencies, again for North America. We see, in the top left panel, that the absolute tendencies of sulfate condensation (light purple) on the nucleation mode or sulfate production (dark purple) for the hydrophilic accumulation mode change substantially $(\sim 10 \times)$ but their fractional tendencies change less, especially when the process is important. Similarly, in the bottom left and top right panel, the absolute tendencies for redistribution (red) are changed by a factor $5-10 \times$, while their fractional tendencies change with less than $10 \%$. The obvious exception to this is the tendency for aging of the accumulation and coarse modes, due to sulfate condensation (brown) in all panels that show substantial changes in both absolute and fractional tendencies. Similar conclusions can be drawn for other regions (not shown).

\section{Conclusions}

We present a pathway analysis of aerosol processes in the Earth's atmosphere. This pathway analysis is a budget of mass and number tendencies due to primary emissions (including instant condensation of soluble biogenic emissions), nucleation, $\mathrm{H}_{2} \mathrm{SO}_{4}$ condensation and in-cloud production, coagulation, aging and wet and dry deposition as well as sedimentation. This budget is constructed from monthly averaged model tendencies due to these processes as modeled by ECHAM5.5-HAM2. To our knowledge, this is the first time such a detailed budget for global aerosol processes has been constructed.

The model ECHAM-HAM represents the aerosol species sulfate, organic matter, black carbon, sea salt and dust with seven distinct modes of four size classes (nucleation, Aitken, accumulation and coarse) and two hygroscopic classes (hydrophobic and hydrophilic). Each mode is presented by a number of tracers: one for its number density and from one to five for the mass densities of its constituent species. Aerosol in ECHAM-HAM can thus be both externally and internally mixed. The M7 microphysics module in ECHAM-HAM is also implemented in regional aerosol models like COSMO and HIRLAM, and is rather similar to the GLOMAP module in the global aerosol model HadGEM-UKCA.

The pathway analysis gives an unprecedented view of how global aerosol is processed. First, aerosol mass and numbers are influenced by quite different processes. A striking example is the hydrophilic accumulation mode. Over most of the globe, its aerosol mass results from condensation and incloud production of $\mathrm{H}_{2} \mathrm{SO}_{4}$ or primary emission of sea salt, while its numbers are determined by growth of hydrophilic Aitken particles. Next, our analysis shows there is a rather 
Hydrophilic coarse mode
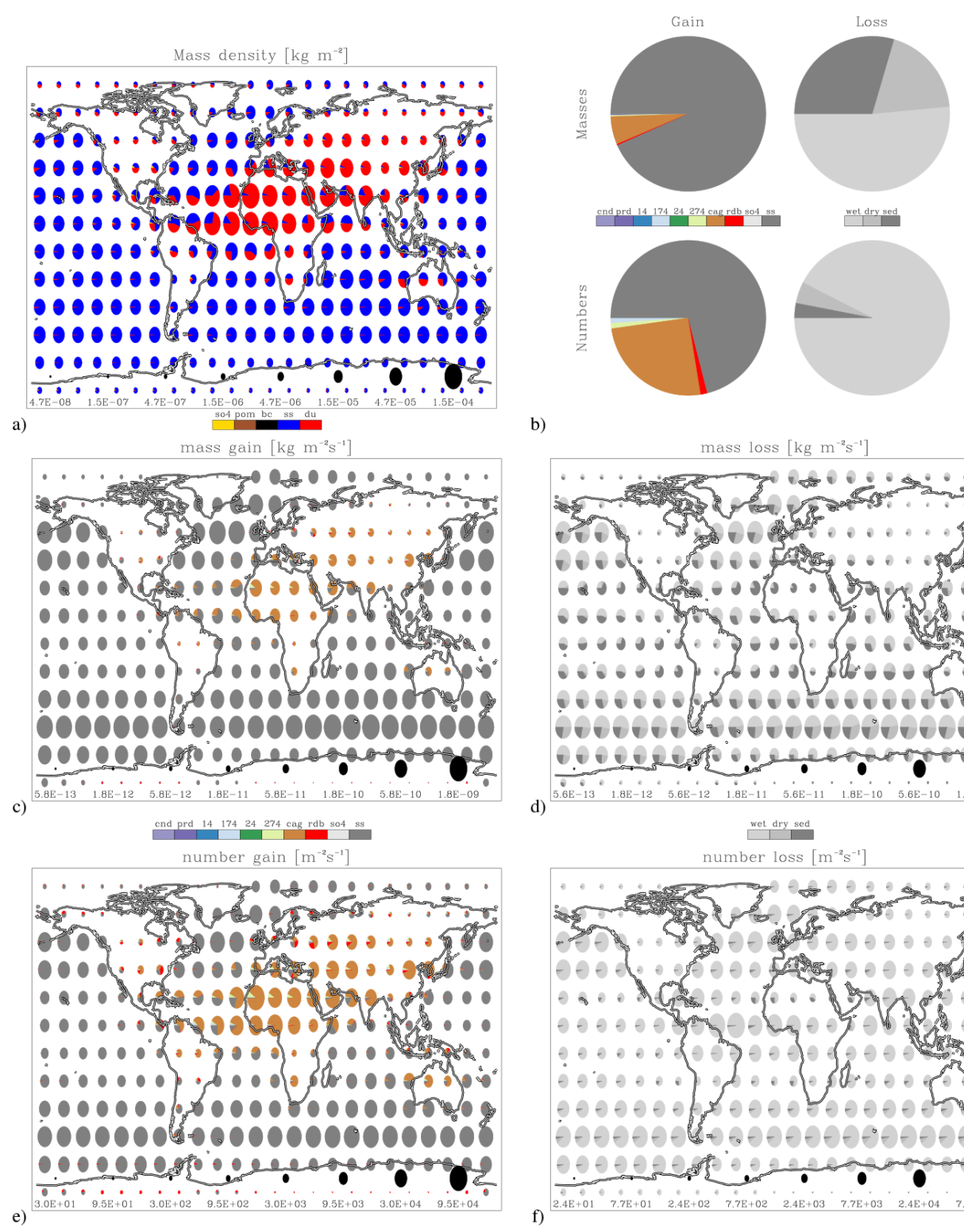

b)
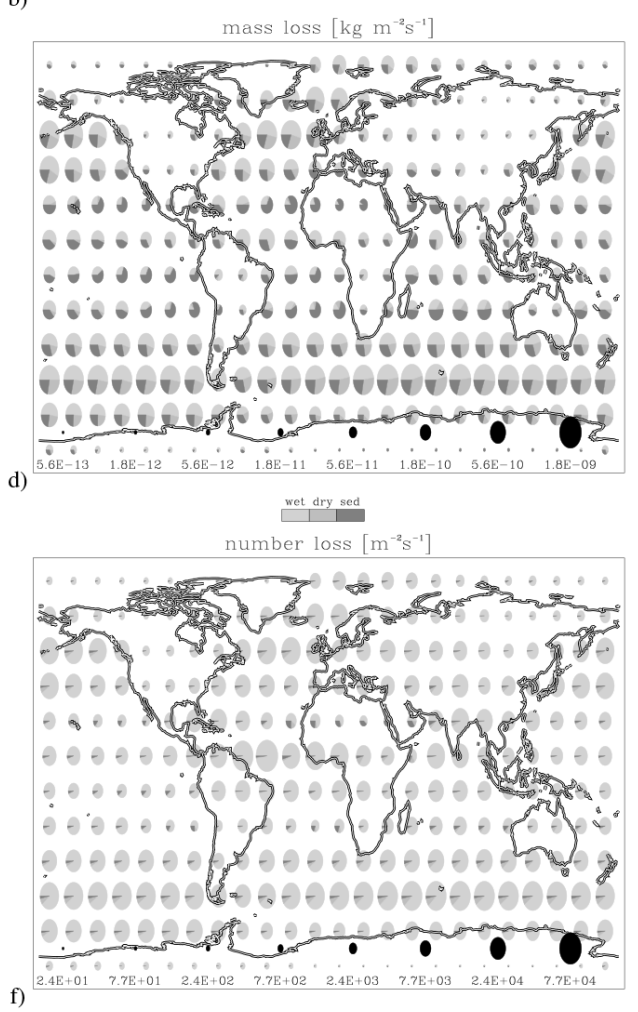

Figure 22. Global distribution of annual burdens (a) and tendencies (b, c, d, e and $\mathbf{f})$ of the hydrophilic coarse mode. The colors indicate either species (defined in Table 3) or processes (defined in Table 2). The pie chart shows fractional contributions, while the radius of the pie indicates total column burden or total column tendency (logarithmic scale as shown in black at the bottom of panels a, c, d, e and f). Panel b shows a global average of the tendencies.

stable hierarchy of importance among the processes, with some processes contributing significantly and others hardly to the aerosol evolution. Among the significant processes, the dominant process differs substantially with region, altitude and season. Our analysis maps out these variations. The coarse modes are mostly governed by primary emissions of sea salt and dust. The evolution of these modes is very distinct and almost entirely decoupled from that of the smaller nucleation, Aitken and accumulation modes. The latter modes are also influenced by primary emissions (of sul- fate and carbons), but $\mathrm{H}_{2} \mathrm{SO}_{4}$ condensation, in-cloud production of $\mathrm{H}_{2} \mathrm{SO}_{4}$ and coagulation often play more substantial roles. Coagulation is only important among the smaller and more numerous modes, where it serves as a loss term (coagulation barely adds mass to the larger modes). Particle growth is shown to be an important process for introducing large numbers of particles into the Aitken and accumulation mode. The analysis also shows how the aging timescale of hydrophobic organic matter and black carbon or hydrophobic dust differs by an order of magnitude across the 

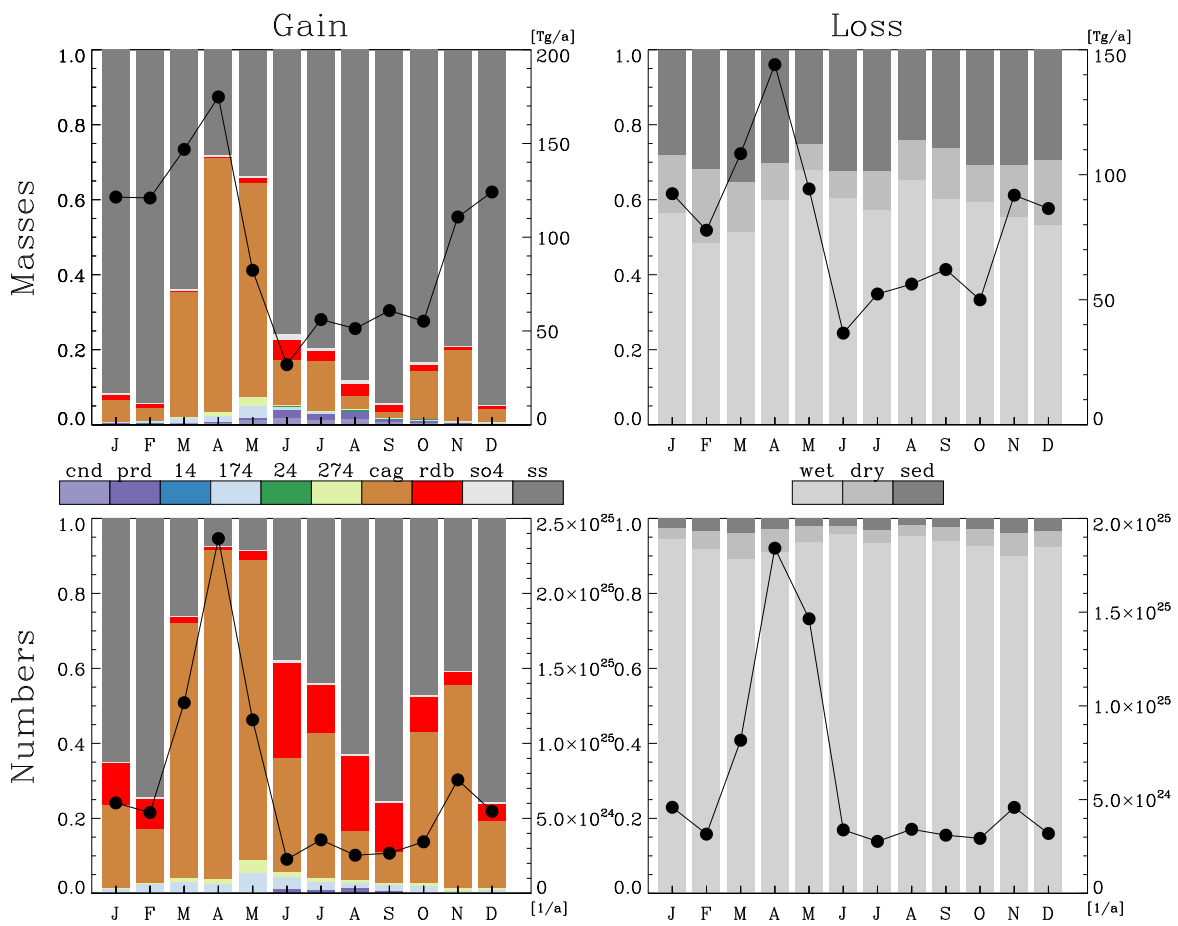

Figure 23. Seasonal cycle of regional tendencies of the hydrophilic coarse mode over East Asia (see Fig. 1). The colored bars show fractional tendencies (left axis) for the processes defined in Table 2. The solid line (right axis) shows the total tendency.
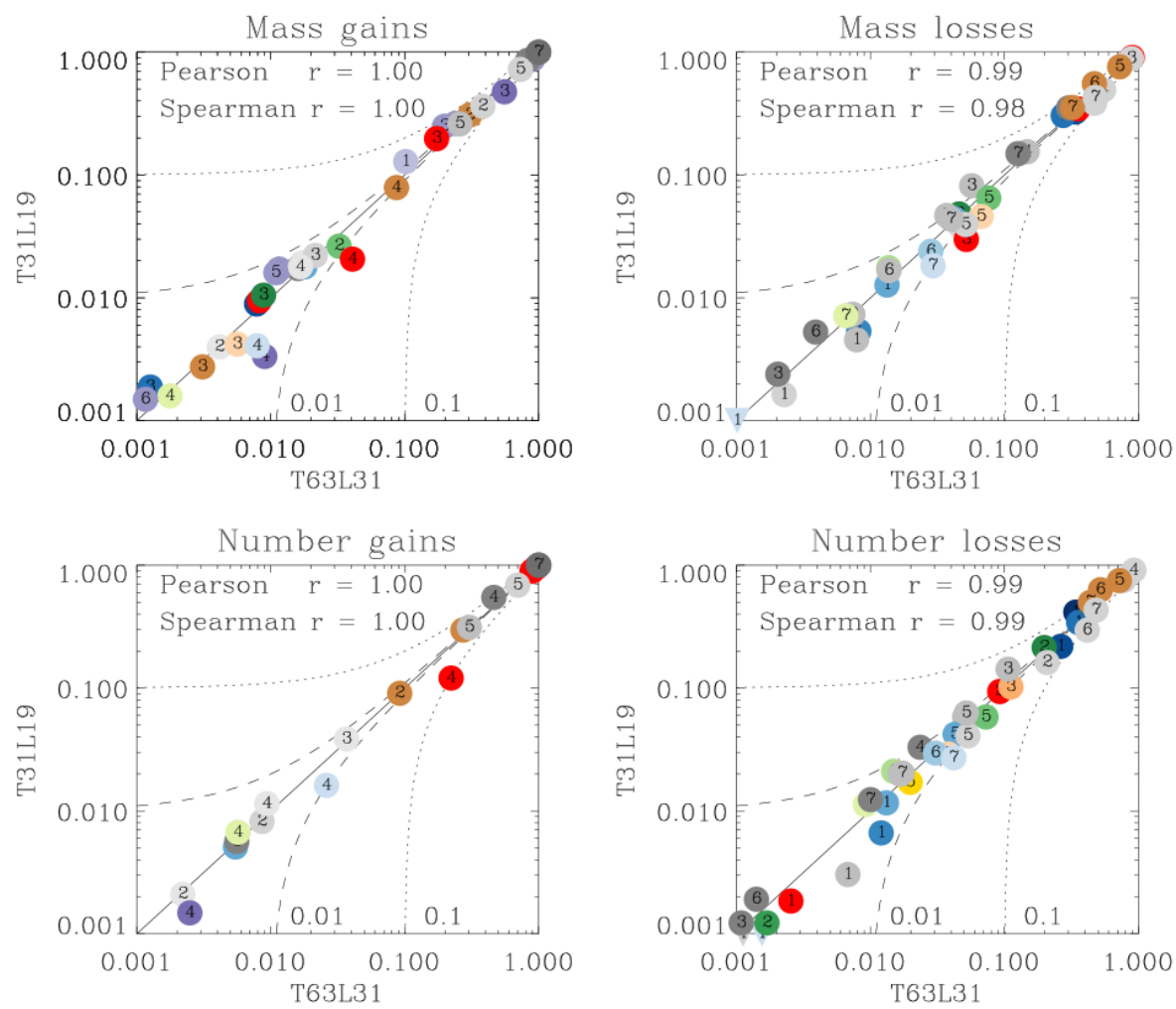

Figure 24. Fractional tendencies for the T31L19 low-resolution experiment versus the baseline T63L31 high-resolution experiment. Colors indicate processes (Table 2), numbers indicate modes (Table 3). Results are shown for North America. 

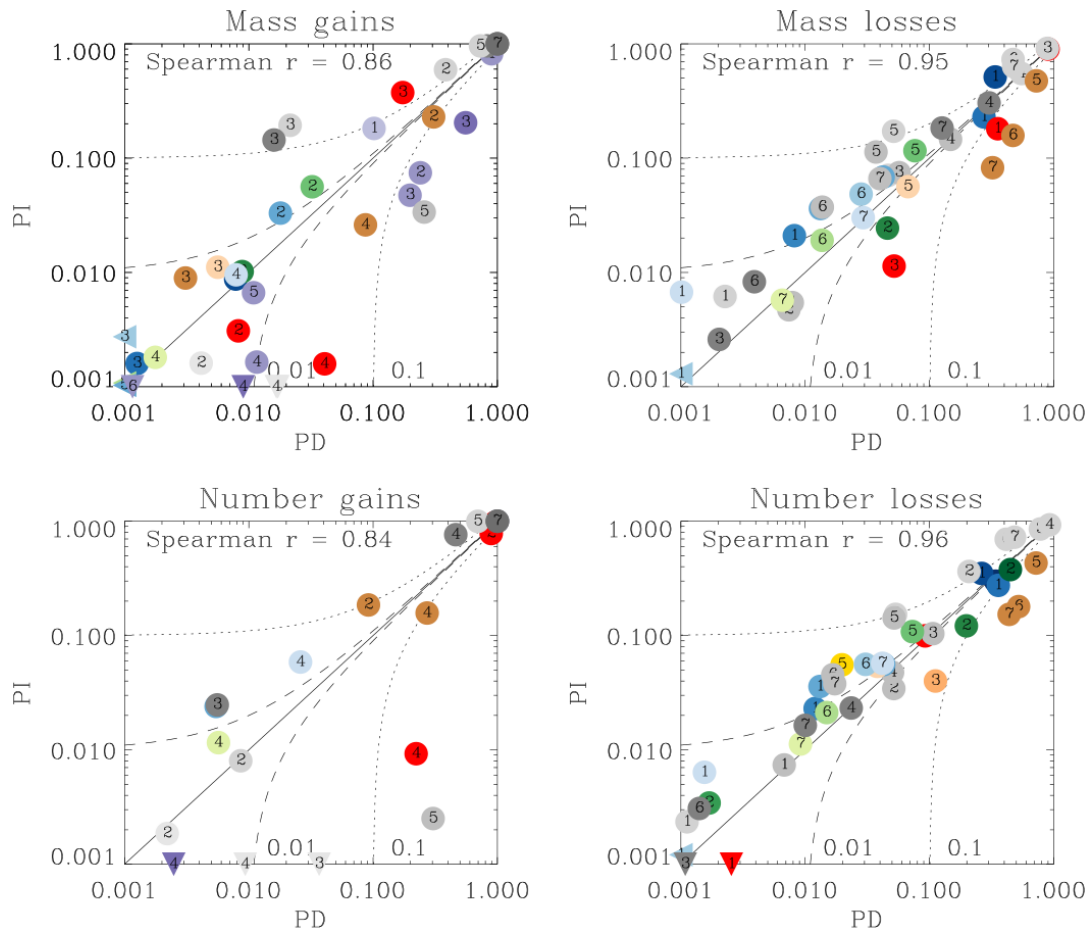

Figure 25. Fractional tendencies for the pre-industrial experiment versus the present-day experiment. Colors indicate processes (Table 2), numbers indicate modes (Table 3). Results are shown for North America.
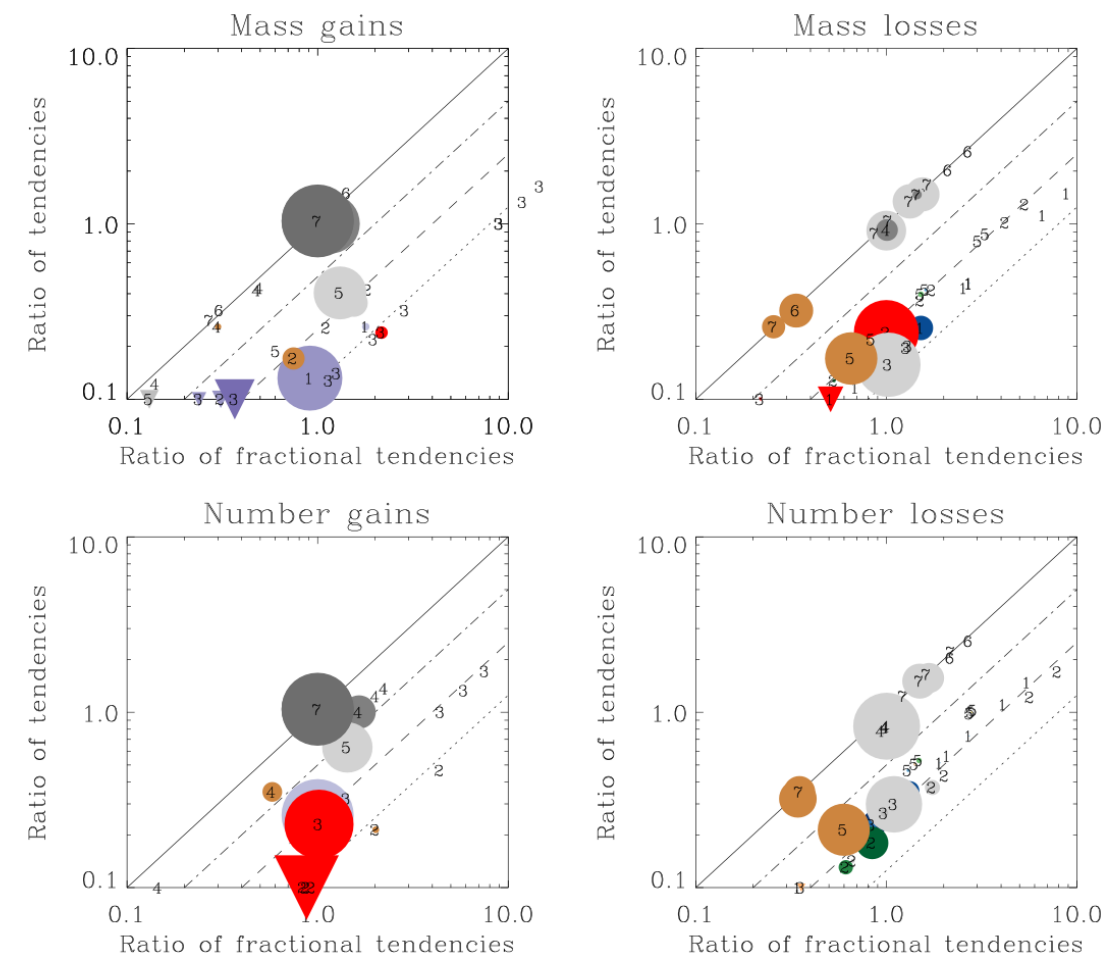

Figure 26. Pre-industrial (PI) to present-day (PD) ratios of absolute tendencies against PI to PD ratios of fractional tendencies. Colors indicate processes (Table 2), numbers indicate modes (Table 3). The size of the symbol indicates fractional tendency in the PD experiment, with the largest symbols having a fractional tendency of about 1 (linear scale). The slanted lines represent $y=2^{-n} x$, with $n=0,1,2,3$. Results are shown for North America. 
globe, even when only considering major source regions. Finally, we present species compositions of each mode resulting from the aforementioned processes. It shows in particular the dominant contribution of sulfate to hydrophilic accumulation mode aerosol on the Northern Hemisphere.

Interestingly, the hierarchy of importance for the aerosol processes is relatively unaffected by what are normally considered major changes in numerical experimental setup. We have conducted experiments with coarser grid resolutions or pre-industrial emissions that lead to changes in the overall simulation (e.g., see Table 3), while leaving the hierarchy intact. Whenever we saw a change, it usually concerned two major processes that exchanged their relative importance. Most notably, when using pre-industrial emissions, aging of hydrophobic aerosols slows down and wet deposition becomes a more important pathway for removal of hydrophobic aerosol. Changes in grid resolution (from T63L31 to T31L19) have less effect on process hierarchy than changing the emissions.

A pathway analysis may be used in several ways. First of all, it provides a detailed narrative of how aerosol is processed. Second, it offers ideas for the reduction of complexity in aerosol models. Current state-of-the-art aerosol modules require a significant part of the overall resources required for global (climate) simulations. Third, a pathway analysis helps to prioritize model improvement as a clear hierarchy in importance of the processes was found. Even though the processes are modeled with various degrees of abstraction, the magnitude of their effect should be reasonable. Fourth, by identifying where and when what processes dominate, a process-based evaluation of a model against relevant observations should become easier. Finally, and related to the last two points, a pathway analysis offers suggestions as to what kind of structural error may affect aerosol simulations.

Future work will include a significant reduction of complexity of M7, the aerosol microphysics routine in ECHAMHAM. Currently, we are extending our pathway analysis to other models to explore the robustness of our findings.

Acknowledgements. This work was supported by the National Environmental Research Council grant nos. NE/G006148/1 (project AEROS) and NE/J024252/1 (project GASSP). Computational resources were made available by Deutsches Klimarechenzentrum (DKRZ) through support from the Bundesministerium für Bildung und Forschung (BMBF). The first author likes to thank Sebastian Rast (DKRZ) for his kind help in running ECHAM-HAM on Blizzard. The figures in this paper were prepared using David W. Fanning's coyote library for IDL. The authors would like to thank one anonymous reviewer and Dr Peter Colarco for their useful comments during the review stage of this paper.

Edited by: A. Dastoor

\section{References}

Aan de Brugh, J. M. J., Schaap, M., Vignati, E., Dentener, F., Kahnert, M., Sofiev, M., Huijnen, V., and Krol, M. C.: The European aerosol budget in 2006, Atmos. Chem. Phys., 11, 1117-1139, doi:10.5194/acp-11-1117-2011, 2011.

Adams, P. J. and Seinfeld, J. H.: Predicting global aerosol size distributions in general circulation models, J. Geophys. Res., 107, doi:10.1029/2001JD001010, 2002.

Albrecht, B. A.: Aerosols, cloud microphysics, and fractional cloudiness, Science, 245, 1227-1230, 1989.

Angstrom, B. A.: Atmospheric turbidity, global illumination and planetary albedo of the earth, Tellus, XIV, 435-450, 1962.

Bauer, S. E., Wright, D. L., Koch, D., Lewis, E. R., McGraw, R., Chang, L.-S., Schwartz, S. E., and Ruedy, R.: MATRIX (Multiconfiguration Aerosol TRacker of mIXing state): an aerosol microphysical module for global atmospheric models, Atmos. Chem. Phys., 8, 6003-6035, doi:10.5194/acp-8-60032008, 2008.

Beelen, R., Raaschou-Nielsen, O., Stafoggia, M., Andersen, Z. J., Weinmayr, G., Hoffmann, B., Wolf, K., Samoli, E., Fischer, P., Nieuwenhuijsen, M., Vineis, P., Xun, W. W., Katsouyanni, K., Dimakopoulou, K., Oudin, A., Forsberg, B., Modig, L., Havulinna, A. S., Lanki, T., Turunen, A., Oftedal, B., Nystad, W., Nafstad, P., De Faire, U., Pedersen, N. L., Östenson, C.G., Fratiglioni, L., Penell, J., Korek, M., Pershagen, G., Eriksen, K. T., Overvad, K., Ellermann, T., Eeftens, M., Peeters, P. H., Meliefste, K., Wang, M., Bueno-de Mesquita, B., Sugiri, D., Krämer, U., Heinrich, J., de Hoogh, K., Key, T., Peters, A., Hampel, R., Concin, H., Nagel, G., Ineichen, A., Schaffner, E., ProbstHensch, N., Künzli, N., Schindler, C., Schikowski, T., Adam, M., Phuleria, H., Vilier, A., Clavel-Chapelon, F., Declercq, C., Grioni, S., Krogh, V., Tsai, M.-Y., Ricceri, F., Sacerdote, C., Galassi, C., Migliore, E., Ranzi, A., Cesaroni, G., Badaloni, C., Forastiere, F., Tamayo, I., Amiano, P., Dorronsoro, M., Katsoulis, M., Trichopoulou, A., Brunekreef, B., and Hoek, G.: Effects of long-term exposure to air pollution on natural-cause mortality: an analysis of 22 European cohorts within the multicentre ESCAPE project, The Lancet, 6736, 1-11, doi:10.1016/S01406736(13)62158-3, 2013.

Brunekreef, B. and Holgate, S. T.: Air pollution and health., Lancet, 360, 1233-42, doi:10.1016/S0140-6736(02)11274-8, 2002.

Chin, M., GInoux, P., KInne, S., Torres, O., Holben, B. N., Duncan, B. N., Martin, R. V., Logan, J. A., Higurashi, A., and Nakajima, T.: Tropospheric Aerosol Optical Thickness from the GOCART Model and Comparisons with Satellite and Sun Photometer Measurements, J. Atmos. Sci., 59, 461-483, 2002.

Dockery, D., Pope, A., Xu, X., Spengler, J., Ware, J., Fay, M., Ferris, B., and Speizer, F.: An association between air pollution and mortality in six U.S. cities, New Engl. J. Med., 329, 1753-1759, 1993.

Easter, R. C., Ghan, S. J., Zhang, Y., Saylor, R. D., Chapman, E. G., Laulainen, N. S., Abdul-razzak, H., Leung, L. R., Bian, X., and Zaveri, R. A.: MIRAGE: model description and evaluation of aerosols and trace gases, J. Geophys. Res., 109, D20210, doi:10.1029/2004JD004571, 2004.

Ezzati, M., Lopez, A. D., Rodgers, A., Vander Hoorn, S., and Murray, C. J. L.: Selected major risk factors and global and regional burden of disease, Lancet, 360, 1347-1360, doi:10.1016/S01406736(02)11403-6, 2002. 
Feichter, J., Kjellstrom, E., Rodhe, H., Dentener, F., Lelieveld, J., and Roelofs, G.-J.: Simulation of the tropospheric sulfur cycle in a global climate model, Atmos. Environ., 30, 1693-1707, 1996.

Folini, D. and Wild, M.: Aerosol emissions and dimming/brightening in Europe: sensitivity studies with ECHAM5-HAM, J. Geophys. Res., 116, D21104, doi:10.1029/2011JD016227, 2011.

Fuchs, N. A.: The Mechanics of Aerosols, Pergamon Press, Oxford, 1964.

Ghan, S. J. and Schwartz, S. E.: Aerosol properties and processes: a path from field and laboratory measurements to global climate models, B. Am. Meteorol. Soc., 88, 1059-1083, doi:10.1175/BAMS-88-7-1059, 2007.

Ghan, S. J., Liu, X., Easter, R. C., Zaveri, R., Rasch, P. J., Yoon, J.H., and Eaton, B.: Toward a minimal representation of aerosols in climate models: comparative decomposition of aerosol direct, semidirect, and indirect radiative forcing, J. Climate, 25, 6461-6476, doi:10.1175/JCLI-D-11-00650.1, 2012.

Guelle, W., Schulz, M., Balkanski, Y., and Dentener, F.: Influence of the source formulation on modeling the atmospheric global distribution of sea salt aerosol, J. Geophys. Res., 106, 27509, doi:10.1029/2001JD900249, 2001.

Hansen, J., Sato, M., and Ruedy, R.: Radiative forcing and climate response, J. Geophys. Res., 102, 6831-6864, 1997.

Hoose, C., Lohmann, U., Bennartz, R., Croft, B., and Lesins, G.: Global simulations of aerosol processing in clouds, Atmos. Chem. Phys., 8, 6939-6963, doi:10.5194/acp-8-6939-2008, 2008.

Horowitz, L. W., Walters, S., Mauzerall, D. L., Emmons, L. K., Rasch, P. J., Granier, C., Tie, X., Lamarque, J.-F., Schultz, M. G., Tyndall, G. S., Orlando, J. J., and Brasseur, G. P.: A global simulation of tropospheric ozone and related tracers: description and evaluation of MOZART, version 2, J. Geophys. Res., 108, 4784, doi:10.1029/2002JD002853, 2003.

Kazil, J. and Lovejoy, E. R.: A semi-analytical method for calculating rates of new sulfate aerosol formation from the gas phase, Atmos. Chem. Phys., 7, 3447-3459, doi:10.5194/acp-7-3447-2007, 2007.

Kazil, J., Stier, P., Zhang, K., Quaas, J., Kinne, S., O’Donnell, D., Rast, S., Esch, M., Ferrachat, S., Lohmann, U., and Feichter, J.: Aerosol nucleation and its role for clouds and Earth's radiative forcing in the aerosol-climate model ECHAM5-HAM, Atmos. Chem. Phys., 10, 10733-10752, doi:10.5194/acp-1010733-2010, 2010.

Kinne, S., Schulz, M., Textor, C., Guibert, S., Balkanski, Y., Bauer, S. E., Berntsen, T., Berglen, T. F., Boucher, O., Chin, M., Collins, W., Dentener, F., Diehl, T., Easter, R., Feichter, J., Fillmore, D., Ghan, S., Ginoux, P., Gong, S., Grini, A., Hendricks, J., Herzog, M., Horowitz, L., Isaksen, I., Iversen, T., Kirkevåg, A., Kloster, S., Koch, D., Kristjansson, J. E., Krol, M., Lauer, A., Lamarque, J. F., Lesins, G., Liu, X., Lohmann, U., Montanaro, V., Myhre, G., Penner, J., Pitari, G., Reddy, S., Seland, O., Stier, P., Takemura, T., and Tie, X.: An AeroCom initial assessment - optical properties in aerosol component modules of global models, Atmos. Chem. Phys., 6, 1815-1834, doi:10.5194/acp-6-1815-2006, 2006.

Kloster, S., Dentener, F., Feichter, J., Raes, F., van Aardenne, J., Roeckner, E., Lohmann, U., Stier, P., and Swart, R.: Influence of future air pollution mitigation strategies on total aerosol radiative forcing, Atmos. Chem. Phys., 8, 6405-6437, doi:10.5194/acp-86405-2008, 2008.

Koffi, B., Schulz, M., Bréon, F.-M., Griesfeller, J., Winker, D., Balkanski, Y., Bauer, S., Berntsen, T., Chin, M., Collins, W. D., Dentener, F., Diehl, T., Easter, R., Ghan, S., Ginoux, P., Gong, S., Horowitz, L. W., Iversen, T., Kirkevåg, A., Koch, D., Krol, M., Myhre, G., Stier, P., and Takemura, T.: Application of the CALIOP layer product to evaluate the vertical distribution of aerosols estimated by global models: AeroCom phase I results, J. Geophys. Res., 117, D10201, doi:10.1029/2011JD016858, 2012.

Kulmala, M., Lehtinen, K. E. J., and Laaksonen, A.: Cluster activation theory as an explanation of the linear dependence between formation rate of $3 \mathrm{~nm}$ particles and sulphuric acid concentration, Atmos. Chem. Phys., 6, 787-793, doi:10.5194/acp-6-787-2006, 2006.

Langner, J. and Rodhe, H.: A global three-dimensional model of the tropospheric sulfur cycle, J. Atmos. Chem., 13, 225-263, 1991.

Lee, L. A., Carslaw, K. S., Pringle, K. J., and Mann, G. W.: Mapping the uncertainty in global CCN using emulation, Atmos. Chem. Phys., 12, 9739-9751, doi:10.5194/acp-12-9739-2012, 2012.

Lee, L. A., Pringle, K. J., Reddington, C. L., Mann, G. W., Stier, P., Spracklen, D. V., Pierce, J. R., and Carslaw, K. S.: The magnitude and causes of uncertainty in global model simulations of cloud condensation nuclei, Atmos. Chem. Phys., 13, 8879-8914, doi:10.5194/acp-13-8879-2013, 2013.

Lequy, E., Conil, S., and Turpault, M.-P.: Impacts of Aeolian dust deposition on European forest sustainability: a review, Forest Ecol. Manag., 267, 240-252, doi:10.1016/j.foreco.2011.12.005, 2012.

Liao, H., Seinfeld, J. H., Adams, P. J., and Mickley, L. J.: Global radiative forcing of coupled tropospheric ozone and aerosols in a unified general circulation model, J. Geophys. Res., 109, D16207, doi:10.1029/2003JD004456, 2004.

Lin, S.-J. and Rood, R. B.: Multidimensional flux-form semiLagrangian transport schemes, Mon. Weather Rev., 124, 2046-2070, 1996.

Liu, X., Penner, J. E., and Herzog, M.: Global modeling of aerosol dynamics: model description, evaluation, and interactions between sulfate and nonsulfate aerosols, J. Geophys. Res., 110, D18206, doi:10.1029/2004JD005674, 2005.

Liu, X., Easter, R. C., Ghan, S. J., Zaveri, R., Rasch, P., Shi, X., Lamarque, J.-F., Gettelman, A., Morrison, H., Vitt, F., Conley, A., Park, S., Neale, R., Hannay, C., Ekman, A. M. L., Hess, P., Mahowald, N., Collins, W., Iacono, M. J., Bretherton, C. S., Flanner, M. G., and Mitchell, D.: Toward a minimal representation of aerosols in climate models: description and evaluation in the Community Atmosphere Model CAM5, Geosci. Model Dev., 5, 709-739, doi:10.5194/gmd-5-709-2012, 2012.

Lohmann, U. and Feichter, J.: Impact of sulfate aerosols on albedo and lifetime of clouds: a sensitivity study with the ECHAM4 GCM, J. Geophys. Res., 102, 13685-13700, 1997.

Lohmann, U. and Feichter, J.: Global indirect aerosol effects: a review, Atmos. Chem. Phys., 5, 715-737, doi:10.5194/acp-5-7152005, 2005.

Lohmann, U., Salzen, K. V., Mcfarlane, N., and Leighton, H. G.: Tropospheric sulfur cycle in the Canadian general circulation model, J. Geophys. Res., 104, 833-858, 1999. 
Lohmann, U., Stier, P., Hoose, C., Ferrachat, S., Kloster, S., Roeckner, E., and Zhang, J.: Cloud microphysics and aerosol indirect effects in the global climate model ECHAM5-HAM, Atmos. Chem. Phys., 7, 3425-3446, doi:10.5194/acp-7-3425-2007, 2007.

Maher, B., Prospero, J., Mackie, D., Gaiero, D., Hesse, P., and Balkanski, Y.: Global connections between aeolian dust, climate and ocean biogeochemistry at the present day and at the last glacial maximum, Earth-Sci. Rev., 99, 61-97, doi:10.1016/j.earscirev.2009.12.001, 2010.

Makkonen, R., Asmi, A., Korhonen, H., Kokkola, H., Järvenoja, S., Räisänen, P., Lehtinen, K. E. J., Laaksonen, A., Kerminen, V.M., Järvinen, H., Lohmann, U., Bennartz, R., Feichter, J., and Kulmala, M.: Sensitivity of aerosol concentrations and cloud properties to nucleation and secondary organic distribution in ECHAM5-HAM global circulation model, Atmos. Chem. Phys., 9, 1747-1766, doi:10.5194/acp-9-1747-2009, 2009.

McTainsh, G. and Strong, C.: The role of aeolian dust in ecosystems, Geomorphology, 89, 39-54, doi:10.1016/j.geomorph.2006.07.028, 2007.

Monahan, E., Spiel, D., and Davidson, K. L.: A Model of marine aerosol generation via whitecaps and wave disruption, in: Oceanic Whitecaps, edited by: Monahan, E. and Niocaill, G. M., D. Reidel, the Netherlands, 167-174, 1986.

Myhre, G., Samset, B. H., Schulz, M., Balkanski, Y., Bauer, S., Berntsen, T. K., Bian, H., Bellouin, N., Chin, M., Diehl, T., Easter, R. C., Feichter, J., Ghan, S. J., Hauglustaine, D., Iversen, T., Kinne, S., Kirkevåg, A., Lamarque, J.-F., Lin, G., Liu, X., Lund, M. T., Luo, G., Ma, X., van Noije, T., Penner, J. E., Rasch, P. J., Ruiz, A., Seland, Ø., Skeie, R. B., Stier, P., Takemura, T., Tsigaridis, K., Wang, P., Wang, Z., Xu, L., Yu, H., Yu, F., Yoon, J.-H., Zhang, K., Zhang, H., and Zhou, C.: Radiative forcing of the direct aerosol effect from AeroCom Phase II simulations, Atmos. Chem. Phys., 13, 1853-1877, doi:10.5194/acp-13-1853-2013, 2013.

Niemeier, U., Timmreck, C., Graf, H.-F., Kinne, S., Rast, S., and Self, S.: Initial fate of fine ash and sulfur from large volcanic eruptions, Atmos. Chem. Phys., 9, 9043-9057, doi:10.5194/acp9-9043-2009, 2009.

O'Donnell, D., Tsigaridis, K., and Feichter, J.: Estimating the direct and indirect effects of secondary organic aerosols using ECHAM5-HAM, Atmos. Chem. Phys., 11, 8635-8659, doi:10.5194/acp-11-8635-2011, 2011.

Peters, K., Stier, P., Quaas, J., and Graßl, H.: Aerosol indirect effects from shipping emissions: sensitivity studies with the global aerosol-climate model ECHAM-HAM, Atmos. Chem. Phys., 12, 5985-6007, doi:10.5194/acp-12-5985-2012, 2012.

Rasch, P. J., Barth, M. C., Kiehl, J. T., Schwartz, E., Benkovitz, C. M., and America, N.: A description of the global sulfur cycle and its controlling processes in the National Center for Atmospheric Research Community Climate Model, Version 3, J. Geophys. Res., 105, 1367-1385, 2000.

Riipinen, I., Sihto, S.-L., Kulmala, M., Arnold, F., Dal Maso, M., Birmili, W., Saarnio, K., Teinilä, K., Kerminen, V.-M., Laaksonen, A., and Lehtinen, K. E. J.: Connections between atmospheric sulphuric acid and new particle formation during QUEST III-IV campaigns in Heidelberg and Hyytiälä, Atmos. Chem. Phys., 7, 1899-1914, doi:10.5194/acp-7-1899-2007, 2007.
Roeckner, E., Bäuml, G., Bonaventura, L., Brokopf, R., Esch, M., Giorgetta, M., Hagemann, S., Kirchner, I., Kornblueh, L., Manzini, E., Rhodin, A., Schlese, U., Schulzweida, U., and Tompkins, A.: The Atmospheric General Circulation Model ECHAM5, Part I: Model Description, Tech. Rep. 349, Max Planck Institute for Meteorology, Hamburg, 2003.

Roeckner, E., Rokopf, R. B., Sch, M. E., Iorgetta, M. G., and Agemann, S. H.: Sensitivity of simulated climate to horizontal and vertical resolution in the ECHAM5 atmosphere model, J. Climate, 19, 3771-3791, 2006.

Roelofs, G.-J., Lelieveld, J., and Ganzeveld, L.: Simulation of global sulfate distribution and the influence on effective cloud drop radii with a coupled photochemistry sulfur cycle model, Tellus B, 50, 224-242, doi:10.1034/j.1600-0889.1998.t01-200002.x, 1998 .

Roelofs, G. J., Stier, P., Feichter, J., Vignati, E., and Wilson, J.: Aerosol activation and cloud processing in the global aerosol-climate model ECHAM5-HAM, Atmos. Chem. Phys., 6, 2389-2399, doi:10.5194/acp-6-2389-2006, 2006.

Samset, B. H., Myhre, G., Schulz, M., Balkanski, Y., Bauer, S., Berntsen, T. K., Bian, H., Bellouin, N., Diehl, T., Easter, R. C., Ghan, S. J., Iversen, T., Kinne, S., Kirkevåg, A., Lamarque, J.-F., Lin, G., Liu, X., Penner, J. E., Seland, Ø., Skeie, R. B., Stier, P., Takemura, T., Tsigaridis, K., and Zhang, K.: Black carbon vertical profiles strongly affect its radiative forcing uncertainty, Atmos. Chem. Phys., 13, 2423-2434, doi:10.5194/acp-13-24232013, 2013.

Schulz, M., Textor, C., Kinne, S., Balkanski, Y., Bauer, S., Berntsen, T., Berglen, T., Boucher, O., Dentener, F., Guibert, S., Isaksen, I. S. A., Iversen, T., Koch, D., Kirkevåg, A., Liu, X., Montanaro, V., Myhre, G., Penner, J. E., Pitari, G., Reddy, S., Seland, Ø., Stier, P., and Takemura, T.: Radiative forcing by aerosols as derived from the AeroCom present-day and pre-industrial simulations, Atmos. Chem. Phys., 6, 5225-5246, doi:10.5194/acp-6-5225-2006, 2006.

Seinfeld, J. H. and Pandis, S. N.: Atmospheric Chemistry and Physics: From Air Pollution to Climate Change, John Wiley \& Sons, Hoboken, New Jersey, 2006.

Seland, O. Y., Iversen, T., Kirkevåg, A., and Storelvmo, T.: Aerosolclimate interactions in the CAM-Oslo atmospheric GCM and investigation of associated basic shortcomings, Tellus A, 60, 459-491, doi:10.1111/j.1600-0870.2008.00318.x, 2008.

Smith, K. R., Jerrett, M., Anderson, H. R., Burnett, R. T., Stone, V., Derwent, R., Atkinson, R. W., Cohen, A., Shonkoff, S. B., Krewski, D., Pope, C. A., Thun, M. J., and Thurston, G.: Public health benefits of strategies to reduce greenhouse-gas emissions: health implications of short-lived greenhouse pollutants, Lancet, 374, 2091-103, doi:10.1016/S0140-6736(09)61716-5, 2009.

Smith, M. H. and Harrison, N. M.: The sea spray generation function, J. Aerosol Sci., 29, S189-S190, 1998.

Spracklen, D. V., Pringle, K. J., Carslaw, K. S., Chipperfield, M. P., and Mann, G. W.: A global off-line model of size-resolved aerosol microphysics: I. Model development and prediction of aerosol properties, Atmos. Chem. Phys., 5, 2227-2252, doi:10.5194/acp-5-2227-2005, 2005.

Stier, P., Feichter, J., Kinne, S., Kloster, S., Vignati, E., Wilson, J., Ganzeveld, L., Tegen, I., Werner, M., Balkanski, Y., Schulz, M., Boucher, O., Minikin, A., and Petzold, A.: The aerosol-climate 
model ECHAM5-HAM, Atmos. Chem. Phys., 5, 1125-1156, doi:10.5194/acp-5-1125-2005, 2005.

Stier, P., Feichter, J., Kloster, S., Vignati, E., and Wilson, J.: Emission-induced nonlinearities in the global aerosol system: results from the ECHAM5-HAM aerosol-climate model, J. Climate, 19, 3845-3862, 2006a.

Stier, P., Feichter, J., Roeckner, E., Kloster, S., and Esch, M.: The evolution of the global aerosol system in a transient climate simulation from 1860 to 2100, Atmos. Chem. Phys., 6, 3059-3076, doi:10.5194/acp-6-3059-2006, 2006b.

Stier, P., Seinfeld, J. H., Kinne, S., and Boucher, O.: Aerosol absorption and radiative forcing, Atmos. Chem. Phys., 7, 5237-5261, doi:10.5194/acp-7-5237-2007, 2007.

Stier, P., Schutgens, N. A. J., Bellouin, N., Bian, H., Boucher, O., Chin, M., Ghan, S., Huneeus, N., Kinne, S., Lin, G., Ma, X., Myhre, G., Penner, J. E., Randles, C. A., Samset, B., Schulz, M., Takemura, T., Yu, F., Yu, H., and Zhou, C.: Host model uncertainties in aerosol radiative forcing estimates: results from the AeroCom Prescribed intercomparison study, Atmos. Chem. Phys., 13, 3245-3270, doi:10.5194/acp-13-3245-2013, 2013.

Takemura, T., Okamoto, H., Maruyama, Y., Numaguti, A., Higurashi, A., and Nakajima, T.: Global three-dimensional simulation of aerosol optical thickness distribution of various origins, J. Geophys. Res., 105, 17853, doi:10.1029/2000JD900265, 2000.

Tegen, I.: Impact of vegetation and preferential source areas on global dust aerosol: results from a model study, J. Geophys. Res., 107, 4576, doi:10.1029/2001JD000963, 2002.

Tegen, I. and Lacis, A.: Modeling of particle size distribution and its influence on the radiative properties of mineral dust aerosol, J. Geophys. Res., 101, 19237-19244, 1996.

Textor, C., Schulz, M., Guibert, S., Kinne, S., Balkanski, Y., Bauer, S., Berntsen, T., Berglen, T., Boucher, O., Chin, M., Dentener, F., Diehl, T., Easter, R., Feichter, H., Fillmore, D., Ghan, S., Ginoux, P., Gong, S., Grini, A., Hendricks, J., Horowitz, L., Huang, P., Isaksen, I., Iversen, I., Kloster, S., Koch, D., Kirkevåg, A., Kristjansson, J. E., Krol, M., Lauer, A., Lamarque, J. F., Liu, X., Montanaro, V., Myhre, G., Penner, J., Pitari, G., Reddy, S., Seland, Ø., Stier, P., Takemura, T., and Tie, X.: Analysis and quantification of the diversities of aerosol life cycles within AeroCom, Atmos. Chem. Phys., 6, 1777-1813, doi:10.5194/acp-6-1777-2006, 2006.
Textor, C., Schulz, M., Guibert, S., Kinne, S., Balkanski, Y., Bauer, S., Berntsen, T., Berglen, T., Boucher, O., Chin, M., Dentener, F., Diehl, T., Feichter, J., Fillmore, D., Ginoux, P., Gong, S., Grini, A., Hendricks, J., Horowitz, L., Huang, P., Isaksen, I. S. A., Iversen, T., Kloster, S., Koch, D., Kirkevåg, A., Kristjansson, J. E., Krol, M., Lauer, A., Lamarque, J. F., Liu, X., Montanaro, V., Myhre, G., Penner, J. E., Pitari, G., Reddy, M. S., Seland, Ø., Stier, P., Takemura, T., and Tie, X.: The effect of harmonized emissions on aerosol properties in global models an AeroCom experiment, Atmos. Chem. Phys., 7, 4489-4501, doi:10.5194/acp-7-4489-2007, 2007.

Timmreck, C., Graf, H.-F., Lorenz, S. J., Niemeier, U., Zanchettin, D., Matei, D., Jungclaus, J. H., and Crowley, T. J.: Aerosol size confines climate response to volcanic super-eruptions, Geophys. Res. Lett., 37, L24705, doi:10.1029/2010GL045464, 2010.

Twomey, S.: Pollution and the planetary albedo, Atmos. Environ., 8, 1251-1256, 1974.

Vignati, E., Wilson, J., and Stier, P.: M7: an efficient sizeresolved aerosol microphysics module for large-scale aerosol transport models, J. Geophys. Res., 109, D22202, doi:10.1029/2003JD004485, 2004.

Vink, S. and Measures, C.: The role of dust deposition in determining surface water distributions of $\mathrm{Al}$ and $\mathrm{Fe}$ in the South West Atlantic, Deep-Sea Res. Pt. II, 48, 2787-2809, doi:10.1016/S09670645(01)00018-2, 2001.

Weigum, N. M., Stier, P., Schwarz, J. P., Fahey, D. W., and Spackman, J. R.: Scales of variability of black carbon plumes over the Pacific Ocean, Geophys. Res. Lett., 39, L15804, doi:10.1029/2012GL052127, 2012.

Yu, F. and Luo, G.: Simulation of particle size distribution with a global aerosol model: contribution of nucleation to aerosol and CCN number concentrations, Atmos. Chem. Phys., 9, 7691-7710, doi:10.5194/acp-9-7691-2009, 2009.

Zhang, K., O’Donnell, D., Kazil, J., Stier, P., Kinne, S., Lohmann, U., Ferrachat, S., Croft, B., Quaas, J., Wan, H., Rast, S., and Feichter, J.: The global aerosol-climate model ECHAM-HAM, version 2: sensitivity to improvements in process representations, Atmos. Chem. Phys., 12, 8911-8949, doi:10.5194/acp-12-8911-2012, 2012. 